\title{
A Physically Based Algorithm for Downscaling Temperature in Complex Terrain
}

\author{
Peter SHeridan, Simon Vosper, AND SAMANTHA SMITH \\ Met Office, Exeter, Devon, United Kingdom
}

(Manuscript received 18 May 2017, in final form 3 May 2018)

\begin{abstract}
Recent improvements to an algorithm to be used operationally for downscaling screen temperatures from numerical weather prediction models are described. Testing against very high resolution dynamically downscaled screen temperatures and intensive field measurements taken during the Cold-Air Pooling Experiment (COLPEX) is performed. The improvements are based on a physical understanding of the processes involved in the formation of cold-air pools (CAPs) that is informed by recent research. The algorithm includes a parameterization of sidewall sheltering effects that lead to lower temperatures in valley-bottom CAPs on clear, calm nights. Advection and adjustment over exposed hilltops results in higher screen temperatures than on flat ground but lower temperatures relative to the free air above the valley at the same elevation, and a treatment of this effect has also been developed. These processes form the major contributions to the often dramatic small-scale variations in temperature in complex terrain in stable boundary layer conditions, even when height variation is fairly shallow. The improvements result in qualitatively better reproduction of subgrid temperature patterns in complex terrain during CAPs. Statistical forecast errors are subsequently improved.
\end{abstract}

\section{Introduction}

Calm nights with clear skies come with an increased risk of low temperatures and related hazards such as crop damage, or frost and fog affecting road transportation, particularly in valley bottoms. Spatial variation of temperature in complex terrain under these conditions reflects not only the vertical temperature lapse rate within an air mass but also local effects of the terrain. Surface cooling is dominated by radiative losses; air near the surface is then cooled by contact and as a result of vertical turbulent flux divergence (e.g., induced by slope flows) as well as radiative flux divergence, resulting in a stable temperature profile. Sheltering and drainage effects enhance temperature minima in valley bottoms, while the opposite occurs over hilltops (Bogren and Gustavsson 1989; Gustavsson et al. 1998; Pepin and Seidel 2005; Pepin and Norris 2005; Vosper and Brown 2008; Vosper et al. 2014), compared to flat ground at the same altitude, resulting in valley cold-air pools (CAPs). CAPs occur over a range of scales, from the more modest (Bogren and Gustavsson 1989; Gustavsson et al. 1998; Vosper and Brown 2008; Vosper et al. 2014; Sheridan et al. 2014;

Corresponding author: Peter Sheridan, peter.sheridan@ metoffice.gov.uk
Bodine et al. 2009; Mahrt et al. 2014; Whiteman et al. 2004a,b; Steinacker et al. 2007; Clements et al. 2003; Iijima and Shinoda 2000; Whiteman et al. 2008; Lehner et al. 2016a) to large alpine valleys and mountain basins, where long-lasting air stagnation can be associated with serious, cumulative pollution hazards (Lareau et al. 2013; Whiteman et al. 2014; Largeron and Staquet 2016a,b; Chemel et al. 2016).

For valley and hill features that are too small to be resolved by the grid of operational numerical weather prediction (NWP) models, one of several options must be used to obtain a forecast of temperature variation. Dynamical downscaling involves using the output from an NWP model to provide initial and boundary conditions for a similar model running on a finer grid over a local area. While this can be very effective (Vosper et al. 2014; Boutle et al. 2016), the resolution required is currently computationally too expensive for routine weather forecasting purposes. A postprocessing method taking the operational NWP data as input, such as statistical downscaling, is a much cheaper alternative. Statistical downscaling takes advantage of correlations of temperature with various controlling factors (e.g., relating to elevation, topographic shape, or airmass properties) to model subgrid spatial variation of temperature and to produce a forecast at a specific site or sites within a model 


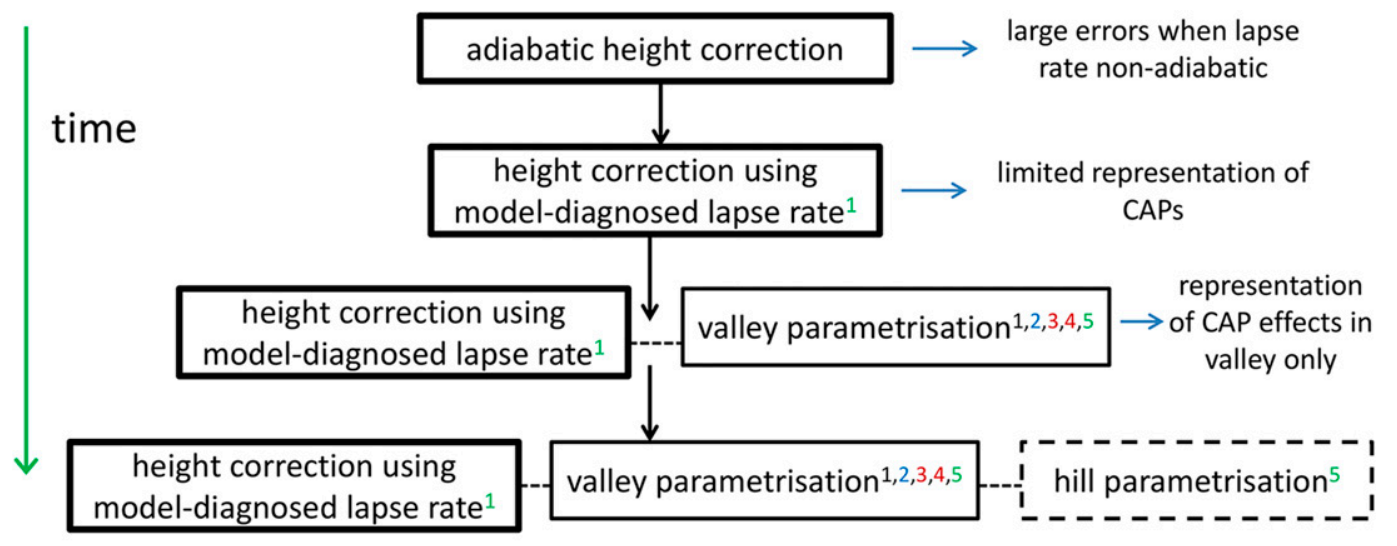

${ }^{1}$ Sheridan et al. (2010)

${ }^{2}$ Vosper and Brown (2008)

${ }^{3}$ Smith et al. (2011)

${ }^{4}$ Sheridan et al. (2014)

${ }^{5}$ This paper

FIG. 1. The evolution of the operational temperature downscaling scheme at the Met Office after successive improvements. Boxes bordered with a solid line indicate components of the scheme that have been implemented operationally. A dashed box border indicates a newly developed component that has not yet been released. A thick solid border indicates a component that has already been described in depth in the literature. An indication of the benefit or shortcomings of each new implementation is given on the right. Key citations (found in the references) for each component are denoted using superscript numbers and are listed beneath the chart, with a blue superscript denoting a paper that provides the scientific basis, red denoting validation of the scientific basis, black denoting a brief mention, and green denoting in-depth description of an operational or proposed operational method.

grid box (e.g., Holden et al. 2011; Hofer et al. 2015; Juga et al. 2013; Krsmanc et al. 2013). Statistical downscaling models trained using large observational datasets are optimized to minimize errors under a wide range of conditions. However, the skill or applicability of this empirical approach is often constrained because of the training data or optimization for certain conditions, particularly when relationships governing predictand variables are not simple or vary under different climatological regimes. In such models, physical basis is largely implicit, rendering them less transparent and more difficult to improve. Physically based downscaling methods (e.g., as used in wind-gust forecasting; Panofsky and Dutton 1984; Brasseur 2001; Della-Marta et al. 2009) aim to retain some of dynamical downscaling's process representativeness while avoiding its computational expense, combining information from NWP models with physical process understanding to model subgrid variation. Their basis in physical understanding affords relative transparency and confidence in their method.

The scheme used operationally at the Met Office to postprocess and downscale forecast screen temperature was developed in response to the poor performance in stable conditions of the previous scheme, which consisted of an adiabatic correction for model height error (height correction). Problems were most obvious during cases with CAPs at the subgrid scale, which an adiabatic height correction cannot represent. The scheme's formulation has subsequently become more sophisticated, relying upon a physical basis. Its evolution is depicted in Fig. 1. Only one development of the scheme, an improvement of the height correction, has been discussed in depth in the literature (Sheridan et al. 2010). Another component (termed valley parameterization) has been implemented operationally but has not been thoroughly described or assessed in the literature. A third component of the scheme, which we propose newly in this paper, is termed the hill parameterization and is not currently implemented.

In brief, the three components of the scheme contribute independently to a final forecast temperature as follows: 1) in the height correction, a local lapse rate is diagnosed from the NWP model to correct for model terrain-height errors arising from subgrid orographic detail, replacing the constant adiabatic lapse rate used before (Sheridan et al. 2010); 2) the valley parameterization represents valley sheltering effects that reduce valleybottom temperatures and give rise to CAPs, following the findings of Vosper and Brown (2008); and 3) the hill parameterization simulates accompanying advection 
and adjustment processes that give rise to warmer temperatures over hilltops during CAP conditions and sharpen the temperature contrast associated with the CAP.

The implementation of the valley parameterization resulted in considerable improvement in the representation of valley-bottom temperatures in strong CAPs. This was revealed (C. Field 2011, Met Office internal report) in testing against observational [described by Price et al. (2011) and Jemmett-Smith (2014)] and 100-m-horizontalresolution model [described by Vosper et al. (2013) and Hughes et al. (2015)] datasets from the Cold-Air Pooling Experiment (COLPEX). A cold bias for hilltop stations remained, however. This motivated the development of the hill parameterization.

This study describes and assesses the individual impact on forecast temperature of the three components of the proposed downscaling scheme: the height correction, the valley parameterization, and the hill parameterization. Section 2 describes the operational NWP model and an idealized model used for parameterization development and briefly summarizes the COLPEX campaign data used to test the downscaling scheme. The downscaling scheme, including development of the hill parameterization, is described in section 3 , and the improvements in performance of the scheme with the inclusion of successive components is demonstrated with reference to numerical models and the observational COLPEX dataset in section 4. A discussion of future work is presented in section 5, with conclusions summarized in section 6 .

\section{Data and numerical models}

The data used to motivate and test developments of the scheme come from the COLPEX field campaign (briefly described below), carried out in 2009-10 (Price et al. 2011). At this time, the operational U.K. regional forecast model used at the Met Office was the 4-kmhorizontal-resolution "UK4" configuration of the Met Office Unified Model (MetUM), and so archived data from this model were used to drive the scheme. The Boundary Layer Above Stationary Inhomogeneous Uneven Surfaces (BLASIUS) model (Wood and Mason 1993) was used in a highly idealized configuration to perform reference simulations of subgrid temperature variation over a scale comparable to the UK4 grid length. Descriptions of these data and models follow.

\section{a. COLPEX field campaign}

The COLPEX field experiment ran for 15 months from mid-January 2009 until mid-April 2010. Measurements taken during the campaign are described by Price et al. (2011), and detailed studies using the observational dataset have been published, including maps of the dense array of temperature sensors used (Sheridan et al. 2014; Jemmett-Smith 2014). These sensors included three masts of 30-50-m height (at locations named Duffryn, Springhill, and Burfield; Fig. 2 in Price et al. 2011), a large number of HOBO temperature sensors and automated weather stations (AWS). In this study, screen temperatures from these sites, stored as 10-min averages, are used to evaluate the downscaling scheme. For the majority of the temperature sensors (HOBOs and tall masts), an accuracy of $0.15^{\circ} \mathrm{C}$ is quoted; for the AWS sensors, accuracy is quoted as $0.5^{\circ} \mathrm{C}$ (JemmettSmith 2014). HOBO sites are further subject to a potential bias of $+1^{\circ}-2^{\circ} \mathrm{C}$ in strong sun, light wind conditions (Jemmett-Smith 2014). Because of a phased setup, data are intermittent (and most sites are unavailable) in the first half of 2009. Between July 2009 and mid-April 2010 availability of good data at the masts and HOBO sites ranged between $70 \%$ and almost $100 \%$, and at the AWSs it typically ranged between $20 \%$ and $40 \%$.

In addition, downscaled temperatures are evaluated against screen temperatures from a 100-m-horizontalresolution nested MetUM configuration, used to model case studies over the array (Vosper et al. 2013, 2014; Hughes et al. 2015). This model configuration used a finer vertical grid compared to operational versions, with double the number of vertical levels, which has been shown to give a better representation of valley CAPs (Vosper et al. 2013).

\section{b. The UK4 model}

For the period of interest (2009-10), this configuration of the operational MetUM used the New Dynamics (Davies et al. 2005) dynamical core, with 70 levels up to roughly 40-km height MSL, running over an area encompassing the British Isles [for further details see Bornemann et al. (2005)]. An hourly archive of standard diagnostic data from the model is available from the period of the COLPEX campaign, with forecasts having been initialized at $0000,0600,1200$, and 1800 UTC each day. To provide continuous data coverage over this period, forecast data up to a lead time of $6 \mathrm{~h}$ have been used, since long lead times potentially introduce errors as the forecast synoptic conditions diverge from the analysis. This consideration is important since it is desirable to examine the performance of the downscaling scheme directly, with as few compounding errors as possible from the UK4 forecast (most crucially in terms of cloud and wind and their effects on temperature close to the surface).

\section{c. BLASIUS}

The Met Office BLASIUS model (Wood and Mason 1993) was used to provide very high resolution reference simulations for detailed examination of CAP behavior 
in a highly constrained, idealized setting. The simulations also informed development of the hill parameterization and permit validation of the behavior of the downscaling scheme as a whole without effects of extraneous factors that might be present in an operational setting. This model has been used extensively to study flow over orography in stable (Brown and Wood 2003) and unstable (Allen and Brown 2006) boundary layers, as well as to study near-surface effects of gravity waves (Vosper 2004; Vosper et al. 2006; Sheridan and Vosper 2005, 2006; Sheridan et al. 2007). The configuration used was very similar to that used by Vosper and Brown (2008), solving the Boussinesq equations in a terrain-following coordinate system (Gal-Chen and Somerville 1975), employing cyclic lateral boundary conditions, with a horizontal grid spacing of $62.5 \mathrm{~m}$ and 200 vertical levels up to $20000 \mathrm{~m}$, vertical grid spacing stretching from $10 \mathrm{~m}$ at the surface (lowest level at $5 \mathrm{~m}$ ) to roughly $130 \mathrm{~m}$ at $3000 \mathrm{~m}$, and constant increments above this. A firstorder Richardson-number-dependent mixing-length turbulence closure scheme was used. A no-slip lower boundary condition was used with a roughness length of $0.1 \mathrm{~m}$, and Rayleigh damping applied above $15 \mathrm{~km}$. A Coriolis parameter corresponding to $51^{\circ} \mathrm{N}$ (roughly the latitude of the COLPEX campaign) was used (roughly $\left.0.0001 \mathrm{~s}^{-1}\right)$. A force-restore scheme for surface temperature, and a radiation scheme, were applied exactly as Vosper and Brown (2008), with nocturnal longwave radiative cooling controlled by constraining the ratio of

$$
h(x)=\left\{\begin{array}{l}
H \cos ^{2}[\pi(x+P / 2) / L] \\
H \\
0
\end{array}\right.
$$

where $H$ and $L$ are the hill height and combined width of the windward and leeward slopes, respectively, and $P$ is the plateau width. To resemble the terrain scales of the COLPEX campaign, values of $H=150 \mathrm{~m}$ and $L=1 \mathrm{~km}$ are used. In the case of the plateau, $P=2 \mathrm{~km}$ was used; for the hill, $P=0$ was used. The plateau simulations used a domain of 5-km length, hill simulations used 4-km length. (A transect through the plateau terrain can be seen, e.g., in Fig. 3, described in more detail below.) Remaining simulation details are as in Vosper and Brown (2008) except where specified.

\section{Description of the downscaling scheme}

An intermediate grid used in the operational postprocessing system renders it unwieldy for development of individual schemes. Instead, the temperature downscaling downwelling to upwelling radiative flux at the surface to be equal to an adjustable constant $F_{\mathrm{lw}}$ viewed as a representation of cloudiness. The radiation scheme incorporates terrain shading for shortwave radiation, and the same midlatitude winter specification as used by Vosper and Brown (2008) was employed. The simulations principally used for reference corresponded to three sets of conditions, involving geostrophic wind $U$ and $F_{\mathrm{lw}}$ specifications of $\left(U, F_{\mathrm{lw}}\right)=\left(2.5 \mathrm{~m} \mathrm{~s}^{-1}, 0.6\right)$, $\left(5.5 \mathrm{~m} \mathrm{~s}^{-1}, 0.6\right)$, and $\left(5.0 \mathrm{~m} \mathrm{~s}^{-1}, 0.75\right)$. This selection of conditions is somewhat arbitrary, but they may be thought of as representing very stable conditions and two grades of moderately stable conditions by alternate variation of wind speed and degree of nocturnal radiative cooling. The latter was desirable to give the option of investigating if a dependence on $F_{\mathrm{lw}}$ would be useful in the valley parameterization (though this is not pursued in any detail here). A number of other less stable conditions were simulated but produced rather weak temperature variation over the hill and were trivially well forecast by the downscaling scheme. To reduce model spinup time, the 2D simulations were initialized with the final profile from a 6-day-long 1D simulation, corresponding to a time of 0600 UTC. Each 2D simulation was then run for 3.25 days to obtain three contiguous diurnal cycles of temperature variation.

The 2D terrain used comprised a single plateau or hill for each set of conditions, defined by the following equation:

$$
\begin{array}{ll}
\text { for } & (L+P) / 2 \geq|x| \geq P / 2 \\
\text { for } & |x|<P / 2 \\
\text { for } & |x|>(L+P) / 2
\end{array}
$$

algorithm has been developed using an "offline" version in which the same calculations are applied without the intermediate grid. As already stated, the proposed downscaling scheme consists of three components: height correction, valley parameterization, and hill parameterization. The valley parameterization, though already operational along with the height correction, has not been thoroughly described or verified previously in the literature and so is fully described here. The hill parameterization represents new work, and its development will be described at the end of the section. In comparing the individual performance of the scheme components, we will refer to the application of just the height correction alone as the 1-component scheme (1-c), height correction plus valley parameterization as the 2-component scheme (2-c), and applying all three components as the 3-component scheme 
(3-c). The increments applied by the first two scheme components are calculated in succession but do not influence each other. The hill parameterization calculation uses the heightcorrected data but is independent from the valley parameterization (the valley and hill parameterizations are never both active in the same location). Increments from the different components are combined additively.

\section{a. Height correction}

The height correction was described by Sheridan et al. (2010). This involves diagnosing a local value of $d T / d z$ (i.e., negative of lapse rate) from the driving model (here UK4) level-1 temperatures and height variations within the $8 \times 8$ grid of points nearest to the point of interest (POI). Multiplied by the model height error $\delta H$, this represents a temperature correction to account for the difference between the driving-model surface height and the "true" surface height (measured elevation or from a 100-m terrainelevation dataset). Limits are also applied to the height correction to mitigate unrealistic effects. The magnitude of $d T / d z$ is capped at that of the dry adiabatic lapse rate (DALR) when $d T / d z$ is negative and at 3 times the DALR when $d T / d z$ is positive. A further limit was found to be necessary in cases where a location diagnosed as a local hill in the UK4 model is in fact within a valley and vice versa, that the height correction does not exceed $(70 \mathrm{~m}) \times d T / d z$ in magnitude. This applies to stable conditions only, and so the modification is restricted to locations at which $d T / d z>0$. This follows work by Vosper and Brown (2008) who found that CAP strength plateaus with increasing valley depth for valleys deeper than around $70 \mathrm{~m}$ (their Fig. 12). This number is therefore empirically tailored to the United Kingdom, where the conditions and terrain scales studied by Vosper and Brown (2008) are broadly

$$
\left.\delta T\right|_{v}=\left\{\begin{array}{l}
0 \\
-3(\bar{N} H / \bar{U}-0.2) / 0.4 \\
-3
\end{array}\right.
$$

where $\bar{N}$ and $\bar{U}$ are bulk average Brunt-Väisälä frequency and wind speed diagnosed from the UK4 gridbox profile up to $100 \mathrm{~m}$. Here, $H\left(=h_{\mathrm{avg}}-h_{\mathrm{POI}}\right)$ is the relative depth of the POI below the mean of the terrain heights within a $4-\mathrm{km}$ box centered on the POI derived from a $100-\mathrm{m}-$ resolution terrain-height dataset. The valley parameterization is applied exclusively to POIs below $h_{\text {avg }}$.

\section{c. Hill parameterization}

It was initially expected that the height correction would adequately correct temperatures in hilltop areas typical. Before the application of this constraint, excessive cooling was found in partially resolved valleys. A less crude, more general constraint could be devised in future.

\section{b. Valley parameterization}

In highly stable conditions, temperature variation is not controlled solely by altitude; local variations related to terrain shape and sheltering may be much more significant (Vosper and Brown 2008). In such cases the height correction generally corrects temperature in the appropriate sense, but leaves a shortfall in the intensity of temperature minima. The valley parameterization was developed to represent the impact of these local sheltering effects, following from findings of Vosper and Brown (2008), who used an idealized two-dimensional (2D) model to demonstrate that, for a given set of background conditions, the contrast between valley-bottom and hilltop temperatures is controlled by a nondimensional valley depth $\tilde{N} H / \tilde{U}$ (where $H$ is the valley depth, and $\tilde{N}$ and $\tilde{U}$ are the BruntVäisälä frequency and wind speed in a layer adjacent to the surface) that determines the degree of decoupling between the valley and the external atmosphere due to sheltering by the valley sides. In the valley parameterization, $\tilde{N} H / \tilde{U}$ is diagnosed from UK4 data and highresolution terrain data [we use an overbar notation, e.g., $\bar{N}$, to distinguish this diagnosed parameter from that of Vosper and Brown (2008)]. Recent studies have validated the principle of the parameterization using observational data (Smith et al. 2010; Sheridan et al. 2014) and examined how sheltering influences the balance of thermal fluxes within complex terrain (Vosper et al. 2014). The following function, based on Fig. 13 of Vosper and Brown (2008), describes the modification $\left.\delta T\right|_{v}$ ( $v$ for valley) applied to screen temperatures by the valley parameterization,

$\begin{array}{ll}\text { for } & \bar{N} H / \bar{U}<0.2 \\ \text { for } & 0.2 \leq \bar{N} H / \bar{U}<0.6, \\ \text { for } & \bar{N} H / \bar{U} \geq 0.6\end{array}$

within a UK4 grid box during CAP cases, given the sharpest vertical temperature gradients occur in the valley bottom. Comparisons against the COLPEX dataset, however, found a large cold bias in height-corrected UK4 temperatures during strong CAPs over hilltops, necessitating the development of this component of the scheme.

To illustrate the problem and its cause, potential temperatures extracted directly from UK4, and downscaled using the 2-component scheme, are compared to observed potential temperatures in Fig. 2. (Potential temperatures allow direct comparison of measurements 


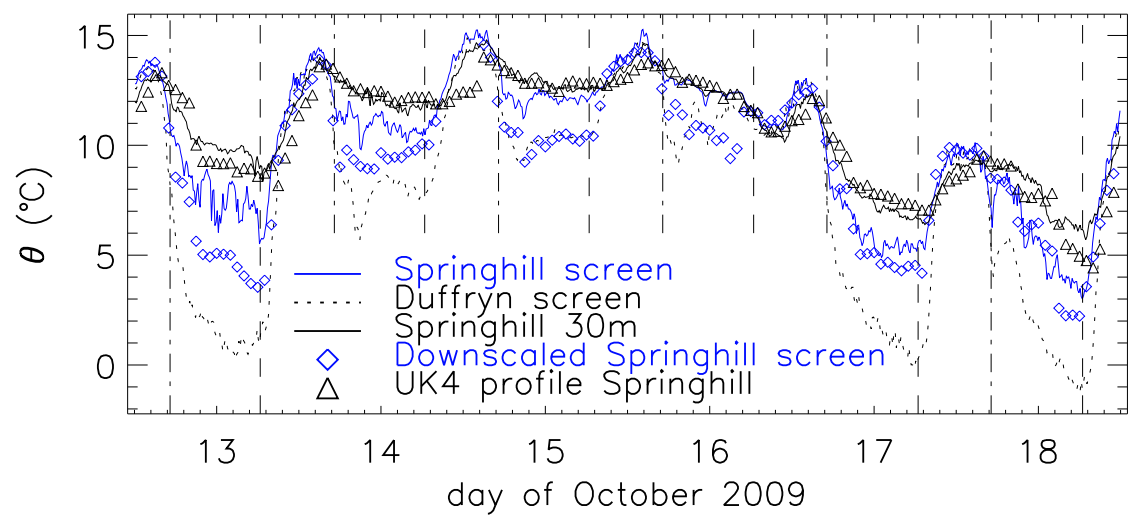

FIG. 2. Time series from 12 to 18 Oct 2009 of observed screen (blue line) and 30-m (black line) potential temperature from the Springhill mast, screen potential temperature from the Duffryn mast (black dotted line), downscaled screen potential temperature at Springhill (blue diamonds), and UK4 gridbox potential temperature at the height of the Springhill mast (black triangles). Vertical lines have been added to indicate sunrise (dashed) and sunset (dot-dashed) times.

and predictions at different heights and conveniently reflect atmospheric stability, and they will be used in place of temperatures in much of the remainder of the paper.) The figure depicts time series of observations at a hilltop mast at Springhill farm, and a valley-bottom site, Duffryn, alongside 1-component scheme potential temperatures. Also included is the potential temperature interpolated from the corresponding UK4 gridbox profile at the height (MSL) of the mast at screen level. The latter will be termed the "environmental potential temperature" $\theta_{\text {env }}$. Note that the Duffryn observations are included only to show the presence of nocturnal cold pools. The cold hilltop bias in downscaled temperatures can be seen by comparing blue points (downscaled) to the blue line (observed). Meanwhile, there is strong correspondence between the mast 30-m potential temperature and $\theta_{\text {env. }}$. This is since the mast protrudes above the shallow hilltop inversion, while the UK4 profile this far from the model surface is not subject to the strong vertical temperature gradients present over nearsurface grid points in stable conditions. Thus, both sample the potential temperature of the roughly neutral residual layer within the overlying air mass, and the comparison represents a verification of the model airmass temperature.

It can be seen that the screen observations at Springhill consistently lie between the downscaled potential temperature and $\theta_{\text {env }}$. This is because cooling of air occurs as it passes over the hilltop surface: if air above the adjacent valley advects to meet and pass over the hill, its temperature adjusts toward the hill surface temperature as a result of turbulent coupling above the hill's surface so that, for instance, the Springhill temperature observed is reduced relative to $\theta_{\text {env. }}$. Sheridan et al. (2014) found a similar relationship between air on hilltops or high up valley sides and temperatures observed by radiosondes flown up through the core of the valley during CAPs. The degree of cooling depends on the extent to which the air can adjust: air at the windward side of the hilltop will have spent less time adjusting than air that has traveled all the way across the hilltop and should be warmer. Put simply, this represents an advective heat source over hills. In Fig. 3, a vertical potential temperature cross section taken from an idealized BLASIUS simulation of flow over a hill under clear skies with a background wind of $2.5 \mathrm{~m} \mathrm{~s}^{-1}$ is used to highlight this process schematically; the layer of cooled air that forms over the hill represents an internal boundary layer (IBL). Conversely, in the same conditions in valleys, or even over flat ground near the surface, the broadly terrain-following motion of air means that it should be closer to equilibrium with the surface, so that this effect is particular to exposed hilltops.

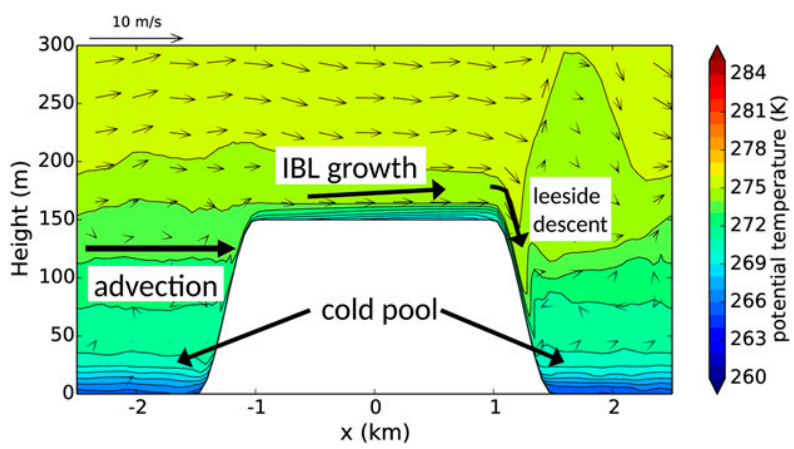

FIG. 3. Snapshot of potential temperature and wind vectors from an idealized 2D BLASIUS simulation at a time of 0740 local time (LT) (essentially the coldest point in the night) over plateau terrain with $U=2.5 \mathrm{~m} \mathrm{~s}^{-1}$ (flow from left) and $F_{\mathrm{lw}}=0.6$, highlighting the processes involved in formation and adjustment of the boundary layer encountering the plateau that are represented in the hill parameterization. 

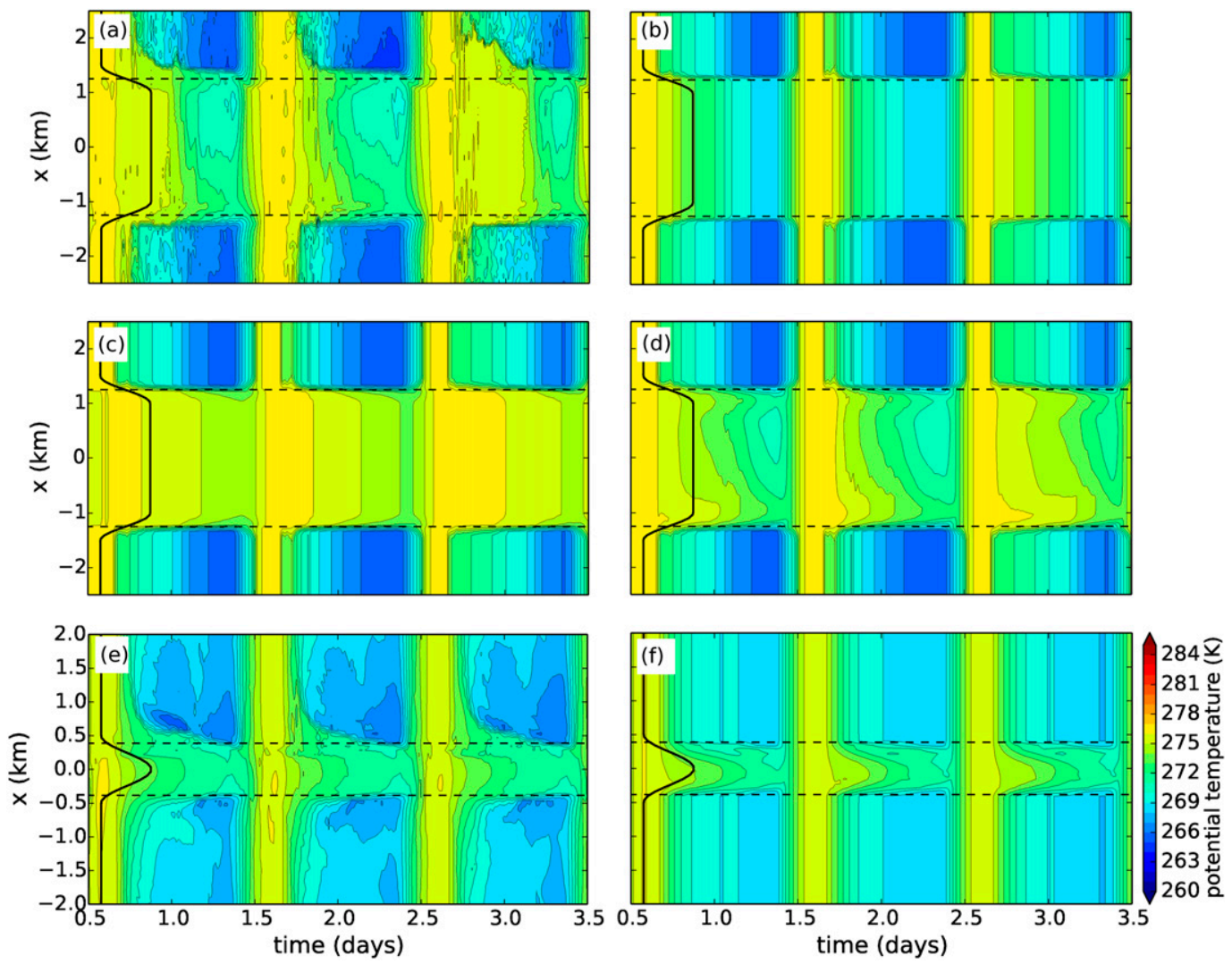

FIG. 4. Time-distance plots (LT) of 5-m potential temperature from three days of (a) an idealized BLASIUS simulation over plateau terrain with $U=2.5 \mathrm{~m} \mathrm{~s}^{-1}$ and $F_{\mathrm{lw}}=0.6$ (see text for explanation) and from corresponding downscaling calculations (b) using the existing scheme involving valley parameterization, (c) modifying temperatures above the mean surface by reading off the mean profile at the same height, and (d) using the hill parameterization to determine temperatures above the mean surface. (e), (f) As in (a) and (d), respectively, but with narrow hill orography and with $U$ increased to $5.5 \mathrm{~m} \mathrm{~s}^{-1}$. Sunrise and sunset times are roughly 0800 and 1600 LT (or 0.33 and 0.67 into each day), respectively. The profile of the terrain with distance through the domain is shown on the left of each panel, and dashed lines indicate where the terrain intersects the mean surface. Flow is in the positive $x$ direction.

The idealized 2D BLASIUS simulations, as discussed in section 2, offer another way of examining CAP behavior and deficiencies in the downscaling scheme's representation of the temperature pattern over hilltops, this time under controlled conditions with simple terrain. Hovmöller-style plots of simulated diurnal temperature variation across the $2 \mathrm{D}$ domain were created (an example is shown in Fig. 4a) and give a useful summary of the spatiotemporal temperature pattern. Comparisons with the 1-, 2-, and 3-component downscaling schemes can be made by applying a given scheme to the points of a gridded terrain model identical to the model terrain, and plotting in the same way as the model temperature field. Since screen temperatures would have required some interpolation between the surface and the first model level above ground, temperatures at the height of the first model level, $5 \mathrm{~m}$, are used. In the absence of a profile from a mesoscale model to drive the downscaling scheme when comparing with the BLASIUS simulations, downscaling was performed using the domain-average vertical profile (AGL) from the BLASIUS simulation itself. While the profile from the 1D initialization of the simulation at an equivalent time could have been used, profiles were found to be significantly transformed by flow over the terrain compared to flow over an infinite plain, so this would not be representative. Imagining that the periodic BLASIUS domain represents subgrid variation in an infinite series of identical mesoscale model grid boxes, it is clear that there is no terrain-height variation in this notional model driving the downscaling scheme. Thus no height correction was applied in comparisons of the downscaling scheme with the BLASIUS simulations (although we retain the " $N$ component" terminology as described above). 
Comparisons using several simplistic "straw man" approaches over hills were initially used to demonstrate the necessity of an approach that properly deals with adjustment over the hilltop. For instance, simply setting the hilltop temperature equal to the environmental temperature from the driving profile at the height of the POI (which we term "design 1"), as Fig. 4c illustrates, was found to result in temperatures almost always too high during significant CAP cases. Also, Fig. 4a shows that temperatures in idealized plateau simulations vary across the plateau because of the slow adjustment of the temperature of air passing over its radiatively cooled surface, which simple designs such as design 1 cannot represent.

In fact, as was the case for the observations in Fig. 2, the simulated hilltop temperatures (Fig. 4a) are bounded by those in Fig. 4c and those in Fig. 4b, which over hilltops represent the environmental and height-corrected temperatures. A pragmatic approach to downscaling over hills would be to find an effective method to adjust between these two bounds, one of which represents the airmass temperature and the other some baseline nearsurface temperature. Equation (14a) of Garratt (1987), which describes the transformation of an air mass through the growth of an IBL on passing from a warm to a cold underlying surface (difference $\Delta \theta$ in potential temperature), offers a plausible physical basis for the adjustment. A formula based on this has been adopted, giving the depth $h_{\mathrm{IBL}}$ of the IBL at a distance $x_{\text {ifc }}$ past the interface according to

$$
h_{\mathrm{IBL}}^{2}=\left(2 A \overline{R_{f}} C_{D}\right) U_{p}^{2}\left(\frac{g \Delta \theta}{\theta_{\text {env }}}\right)^{-1} x_{\mathrm{ifc}},
$$

where we assume a wind direction perpendicular to the interface between warm and cold surfaces and substitute the wind from the gridbox profile at the height of the POI $U_{p}$ for Garratt's vertically uniform wind strength. The drag coefficient may be substituted with $C_{D}=u_{*}^{2} / U_{p}^{2}$, and Garratt's value for $A$ is taken $(A$ is related to the shape of the IBL profile, but is unlikely to vary markedly; Garratt and Ryan 1989). The $\overline{R_{f}}$ refers to a critical layer-flux Richardson number relating buoyancy destruction to shear production of turbulence (Garratt 1987), whose value here is taken according to study over land by Nieuwstadt and Tennekes (1981) as 0.15 , which lies roughly midway between the estimates of Garratt (1987) and Garratt and Ryan (1989). In the case of flow toward a hilltop, the "warm surface" is simply the free surface between adjacent layers of air divided by a streamline approaching a hill, and the cold surface is the surface of the hill (any area protruding through the local mean terrain level). The potential temperature of the warm surface is thus taken as the environmental value $\left(\theta_{\text {env }}\right)$, and that of the cold surface as the height-corrected value ( $\theta_{0}$ here).

In addition to empirical grounds for this choice in Figs. 2 and 4, it seems reasonably justifiable since in a mature stable boundary layer (SBL) the screen temperature may approach that of the surface [as occurs for the simulated mature cold pool in Fig. 6 of Vosper et al. (2014)]. Meanwhile, surface potential temperature change with height is likely to be weaker than for screen potential temperature, perhaps comparable to the adjustment afforded by the height correction under normal conditions, so that the height-corrected temperature is a reasonable approximation of the hill surface temperature (although we note no height correction is applied in these idealized tests). A schematic diagram illustrating the parameters involved in the hill parameterization is given in Fig. 5. The parameterization is only applied if $\theta_{\text {env }}>\theta_{0}$.

The developing IBL is assumed to be bounded above and below by $\theta_{\text {env }}$ and $\theta_{0}$. Garratt and Ryan (1989) suggest the following form for the variation of potential temperature within the IBL as a function of height $z$ above the surface,

$$
\left[\theta(z)-\theta_{0}\right] / \Delta \theta=\left(z / h_{\mathrm{IBL}}\right)^{n},
$$

where the exponent $n$ has been found to vary between 0.5 and 2 in different measurement datasets (Garratt and Ryan 1989). Based on evenly stacked isentropes over the plateau in the early morning in the BLASIUS simulation shown, a linear profile $(n=1)$ was assumed. The distance $x_{\text {ifc }}$ is taken as the distance in the reference upwind direction from the POI over which the terrain protrudes through the mean surface. While this approach takes some liberty with Garratt's assumption of flow over a flat surface and takes no account of the implications of the curvature and slope of the upwind surface for the pathway and adjustment of air arriving at the POI, it is adopted for simplicity (while also found to be effective).

An iterative procedure is required for the computation of $u_{*}$ for which an initial value is derived assuming an IBL depth of $30 \mathrm{~m}$ over which a logarithmic wind profile exists (employing the same roughness length as used in the idealized simulation). The IBL top is considered bounded at the top by $U_{p}$, taken as the crossridge wind component at the level of the POI in the driving profile (though following initial development, in application to real cases in $3 \mathrm{D}$, this was changed to the magnitude of the wind vector at this height), capped at $0.6 \bar{U}$ (the reason for this cap is given in appendix A). This is used to derive a new IBL height using the formula, allowing a new value of $U_{p}$ to be obtained at the 


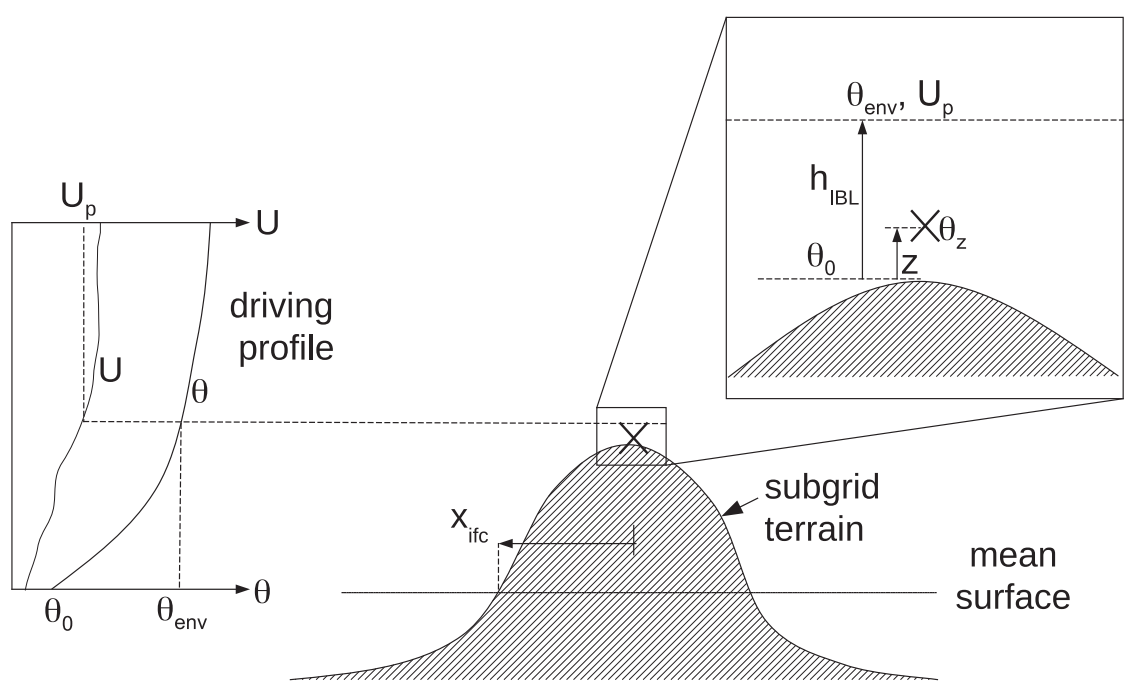

FIG. 5. A schematic depicting the parameters relevant to the hill parameterization to determine temperature at a POI marked with the times sign.

height of the revised IBL top in the driving profile, and hence a new $u_{*}$, and so on until satisfactory convergence is reached. To obtain a near-surface temperature, all that remains is to substitute a height above ground $z$ in Eq. (4)—screen height, for instance.

It is notable in Fig. 4a that both shoulders of the plateau are warm relative to the plateau interior. On the windward side this is a product of the temperature adjustment that occurs across the plateau. On the leeward side, this is ascribed to acceleration and descent associated with gravity waves, such as is evident in Fig. 3. To mimic the relative warmth of the leeward shoulder, a crude treatment of leeside acceleration and descent is incorporated into the hill parameterization, described in the appendix A. The hill parameterization is applied exclusively at POIs lying above $h_{\text {avg }}$.

A final step in the downscaling process is to ensure that the downscaled temperature does not fall below the screen-level dewpoint in the UK4 grid box (latent heat release prevents temperature falling below the dewpoint). This prevents unrealistically low temperatures that were found to be forecast in some cases during preoperational testing, though a future version of the scheme is envisioned in which the effect of dewfall to reduce the dewpoint is parameterized.

\section{Performance of the algorithm}

\section{a. Validation against idealized model simulations}

Figure 4 can now be used to evaluate the 3-component scheme compared to the simpler schemes. Figures $4 \mathrm{~b}-\mathrm{d}$ show temperatures downscaled over plateau orography at $z=5 \mathrm{~m}$ : using the 2-component scheme (i.e., depicting $\theta_{0}$ over hills), applying design 1 (i.e., depicting $\theta_{\text {env }}$ over hills), and using the 3-component scheme, respectively. In valley areas, it is clear that the valley parameterization is performing as intended, cooling valley areas to roughly the right extent (though missing some qualitative spatial features). Over the hill, as expected the BLASIUS model temperatures (Fig. 4a) lie somewhere in between $\theta_{\text {env }}$ and $\theta_{0}$. Meanwhile the 3-component scheme performs well, reproducing the pattern of adjustment over the plateau, including warmer areas at its windward and leeward shoulders. The downslope spread of the warm area on the leeward shoulder in the BLASIUS simulation is a nonlinear effect of this strongly stable flow, dynamically equivalent to a downslope windstorm (Adler et al. 2012; Lehner et al. 2016a,b) and not captured by the current version of the downscaling scheme.

Adjustment and leeside descent express themselves slightly differently in narrower topography (Fig. 4e), but again downscaled temperatures (Fig. 4f) are qualitatively representative, though the warm area over the hill overnight is a little broader in the BLASIUS simulation. This is again due to nonlinear flow considerations on the lee side, but also the windward slope seems more exposed than is suggested by the downscaled results. Performance varied a little under different conditions but screen temperatures in the idealized model and from the algorithm were consistently qualitatively similar, and any differences between the two predominantly did not exceed around $1^{\circ} \mathrm{C}$.

A number of features were adapted when subsequently applying the downscaling algorithm in comparison with observational data and real-case MetUM simulations. These changes are detailed in appendix B. 


\section{b. Comparison with very high resolution MetUM}

The 100-m-horizontal-resolution MetUM simulations of COLPEX cases described by Vosper et al. (2014) and Hughes et al. (2015) provide a realistic dataset against which downscaled temperature fields can be compared in fine detail across the landscape, without being confined, for instance, to observation locations. A comparison is depicted across Figs. 6 and 7 for a clear-night-sky case from COLPEX on 10-11 September 2009. Valley-bottom and hilltop screen temperatures in the MetUM simulations verify well against COLPEX observations in clearsky cases (e.g., Vosper et al. 2014). Figure 7a represents a snapshot of 100-m MetUM screen temperatures.

Figures $6 \mathrm{a}-\mathrm{d}$ show raw UK4 temperatures, temperatures downscaled using the 1-component and 2-component schemes $\left(\theta_{0}\right.$ over hilltop areas), and applying design $1\left(\theta_{\text {env }}\right.$ over hilltop areas), respectively, calculated at the points of the 100-m MetUM grid. The figures show the impact of progressively including more components in the scheme and reveal a similar outcome to the analogous idealized comparison in Fig. 4. The valley parameterization (Fig. 6c), while showing some local differences in the pattern of valley temperatures, represents well the valley-bottom part of the hill-valley contrast associated with the CAP. The height correction on its own (Fig. 6b) misses this, reflecting a more general lapse rate, which at this point is not inverted. Figure $6 \mathrm{c}$ also demonstrates the cold bias in downscaled temperatures over hills when the hill parameterization is not applied. Similarly again to Fig. 4, the temperatures simulated by the 100 -m-resolution MetUM over hilltops (Fig. 7a) are enclosed by $\theta_{\text {env }}$ (Fig. 6c) and $\theta_{0}$ (Fig. 6d). Finally, the addition of the hill parameterization (Fig. 7b) completes a quite credible reproduction of the MetUM screen temperature field of Fig. 7a. The comparison is similar for other times overnight (as discussed below) and other nights when the 100-m-resolution MetUM configuration validates well. One notable feature over broader hilltops is the apparent representation of the so-called thermal belt (Chung et al. 2006) by the downscaling scheme, where the highest temperatures occur not at the highest elevations, but beneath this over a contour band in the upper-terrain slopes.

A more detailed inspection reveals some qualitative differences between MetUM and downscaled temperatures. Low temperatures in smaller hollows picked out in the MetUM temperature field (areas colored green in Fig. $7 \mathrm{a}$, often in steep locations or climbing through saddles as is seen, e.g., along the lower half of the left edge of the panel) seem absent in the downscaled field, suggesting the method of calculating $H$ for downscaling may not be targeting the most influential terrain scales. Also the MetUM temperatures seem to display more along-wind (northeast-southwest) asymmetry across hilltops. Better treatment of high-Froude-number flows by the hill parameterization's leeside descent calculation could improve this.

To illustrate the degree of consistency of the comparison through the diurnal cycle, and place the temperature contrasts depicted into the context of the diurnal variation of temperature, Figs. 8 and 9 repeat the above comparison at 4-hourly intervals through the night of 10-11 September 2009.

\section{c. Comparison with COLPEX observations}

While comparisons with the 100-m MetUM simulations are illustrative for the spatial temperature pattern, a more rigorous test of the scheme is to compare with the COLPEX observations directly. A number of nights on which CAPs occurred during COLPEX were selected as case studies, summarized in Table 1, including several that originally highlighted the hilltop cold bias (cases 1, 2 , and 5), and the strongest cold pools occurring during COLPEX IOPs. These cases were previously used for illustration of cold-pool behavior by Sheridan et al. (2014) and involved clear skies for a continuous period representing most or all of the night, with no significant fog formation. Particularly exposed upland and sheltered valley locations are selected for comparison, which will reflect the temperature contrasts across the terrain that the algorithm aims to capture, and where the hill and valley parameterizations should have the most impact. As already indicated, the algorithm can only perform when driven by a generally good forecast of external factors that affect the near-surface profiles of temperature and wind in a grid box: most notably the background wind and cloud cover. While these factors are considered to be broadly well represented for the cases examined here, a general UK4 temperature bias may occur for some cases/locations (which we infer from the behavior of the model over the diurnal cycle as a whole).

\section{1) VALLEY LOCATIONS}

Figure 10 shows comparisons of raw UK4 temperatures, height-corrected temperatures, and temperatures downscaled using the 3-component scheme, at screen level, against observed temperatures for time series over a diurnal cycle for valley-bottom sites from COLPEX. The figure demonstrates the relatively modest effect that the height correction has on its own, even in very stable conditions. Figures 10a-f show comparisons for Duffryn for cases 1-6 (except case 3 for which Duffryn data were not available, replaced by data from $\mathrm{HOBO} 2$ ). As was found for the majority of valley-bottom sites, screen temperatures are generally well reproduced for each case by the 3-component scheme. Exceptions include case 1, during which a disturbance at 2200 UTC decreases stability, 
raw UK4

(a) $20090910-23$ UTC

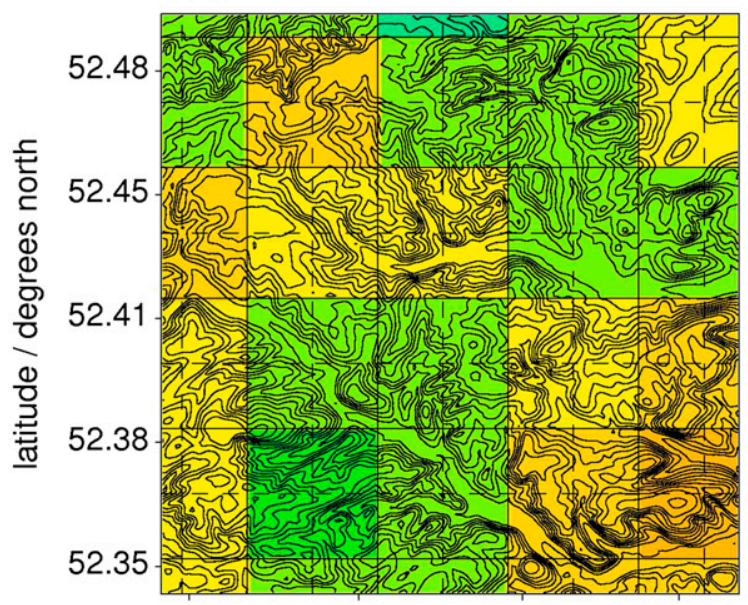

UK4 height correction, valley parameterisation

(c) $20090910-23$ UTC

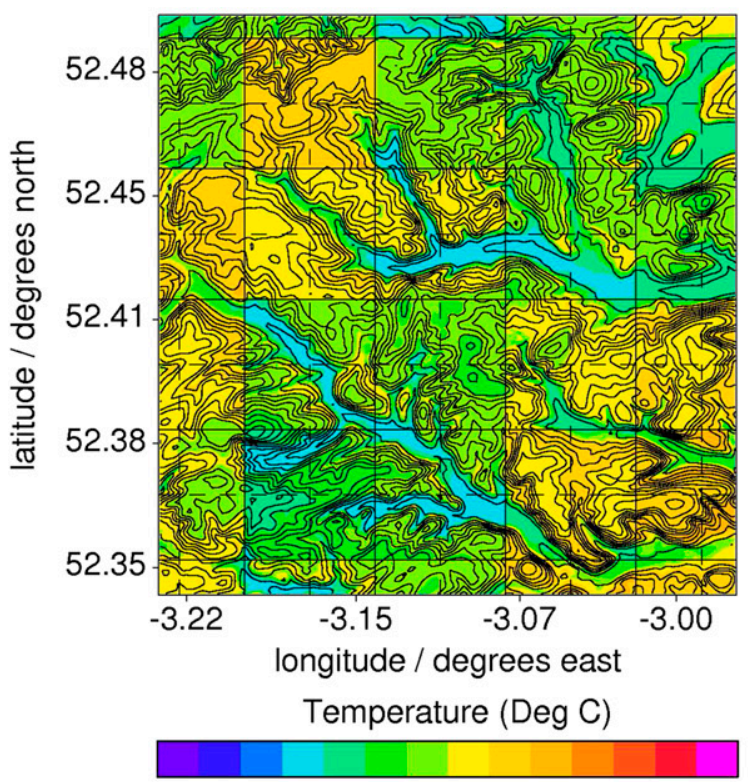

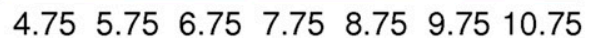

UK4 height correction

(b) 20090910 - 23UTC

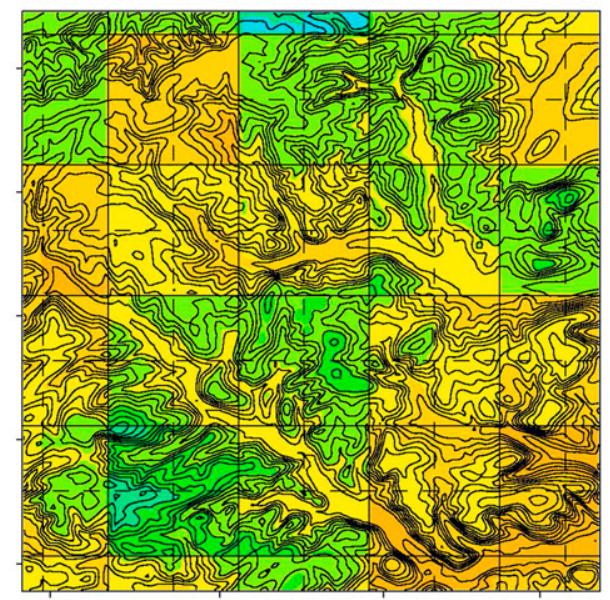

UK4 height correction, valley parameterisation, hills as environment
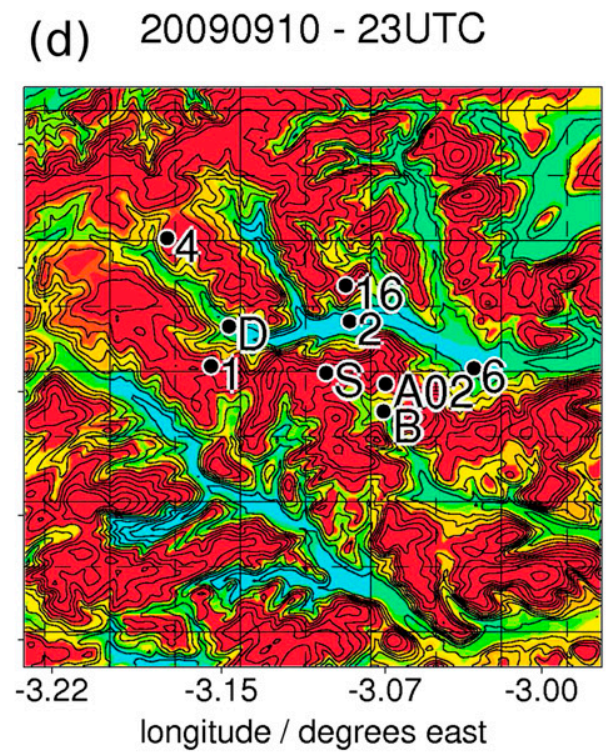

FIG. 6. Maps of partially downscaled screen temperature (colors) at 2300 UTC 10 Sep 2009 over the domain used for nested 100-m-horizontal-resolution MetUM simulations, showing (a) raw UK4 temperatures, (b) temperatures downscaled using height correction only, and (c) temperatures downscaled using the 2-c scheme (forming the lower bound of the hill parameterization over hilltop areas). (d) As in (c), but showing the upper bound of the hill parameterization over hilltop areas. Straight solid lines indicate UK4 gridbox boundaries, and dashed lines delineate the $8 \times 8$ point stencil used to perform the height-correction changes. Terrain contours are shown with intervals of $25 \mathrm{~m}$. In (d), the three principal COLPEX mast sites are marked (D, B, and S), in addition to HOBO or AWS stations used to create Figs. 10 and 11, below. 
(a)

\section{$100 \mathrm{~m}$ model $1.5 \mathrm{~m}$ temperature}

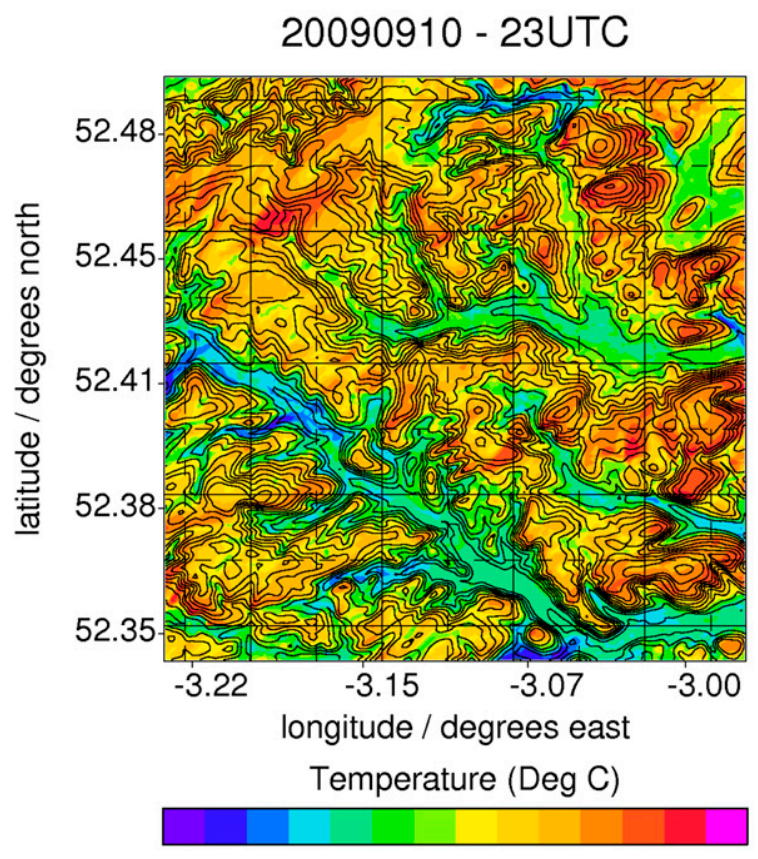

(b)

UK4 height correction, valley and hill parameterisations

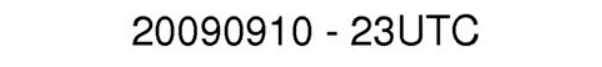

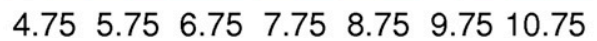

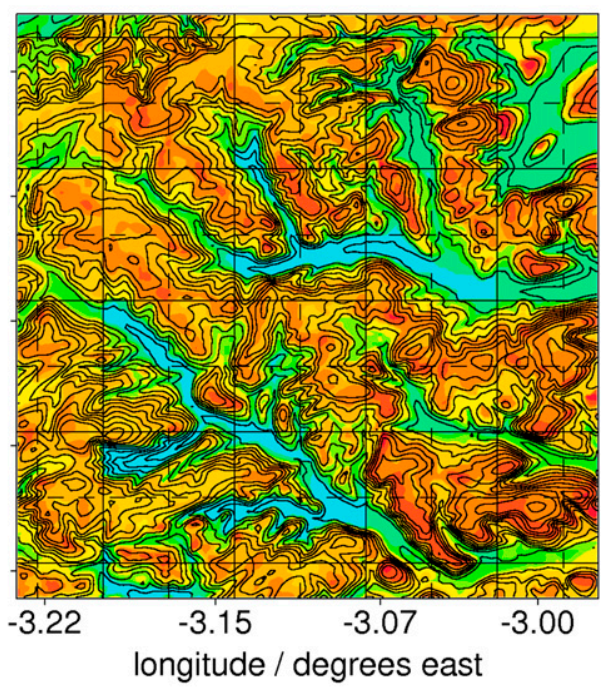

FIG. 7. Maps of screen temperature (color contours) at 2300 UTC 10 Sep 2009 over the domain used for nested 100-m-horizontal-resolution MetUM simulations, showing (a) temperatures from the 100-m-resolution MetUM and (b) temperatures downscaled using height correction, valley parameterization, and hill parameterization. Other aspects of the plots are as in Fig. 6.

reduces $\bar{N} H / \bar{U}$, and results in overestimation of temperature at Duffryn. Valley temperatures overnight during case 3 when snow covered the ground are also overestimated. There also appears to be a significant UK4 model bias apparent during the daytime in case 3 (cf. green and black traces) that may also be masking the full magnitude of the error. The effects of snow on the diurnal temperature range are clearly not very well represented in the scheme. This may be related to radiative effects not modeled properly within the driving model, but it also seems that CAPs over snow cover fall into a different regime, not represented by the valley parameterization, because of snow's effects on surface fluxes (Whiteman et al. 2004b). Stability in the gridbox profile during the day over snow gives rise to a large modification by the valley parameterization that exacerbates the daytime error in downscaled temperatures. This is an artifact of the assumption of clear-sky nocturnal radiative cooling inherent in the valley parameterization that could be mitigated by sensitivity of the valley parameterization to net radiation.

One station, HOBO 6 , is frequently significantly colder than the algorithm predicts during CAPs, as for instance depicted in Figs. $10 \mathrm{~g}$ and $10 \mathrm{~h}$ for cases 4 and 5.
HOBO 6 is in a broad part of the valley, so that the diagnosed valley depth $H$ is slightly smaller than for some other valley-bottom locations, and the valley parameterization applies a slightly weaker adjustment. Of likely greater impact, however, is HOBO 6's situation in a broad confluence of tributaries, with a constriction in the valley profile downvalley, which may influence the temperature through the accumulation of cold air, and flow deceleration due to convergence and obstruction of thermal flows. A similar effect is found to occur at HOBO 7 in an analogous location downvalley from the Burfield mast. Methods of improving the treatment of such locations are not explored here, although approaches that take into account effects of valley cross section on flow dynamics and thermal budget, such as a simple drainage model, might prove useful.

\section{2) Hilltop Locations}

Figure 11 shows comparison of raw UK4 temperatures, height-corrected temperatures $\theta_{0}$, and temperatures downscaled using the 3-component scheme, at screen level, against observed temperatures for time 
$100 \mathrm{~m}$ model $1.5 \mathrm{~m}$ temperature

(a) $20090910-14$ UTC

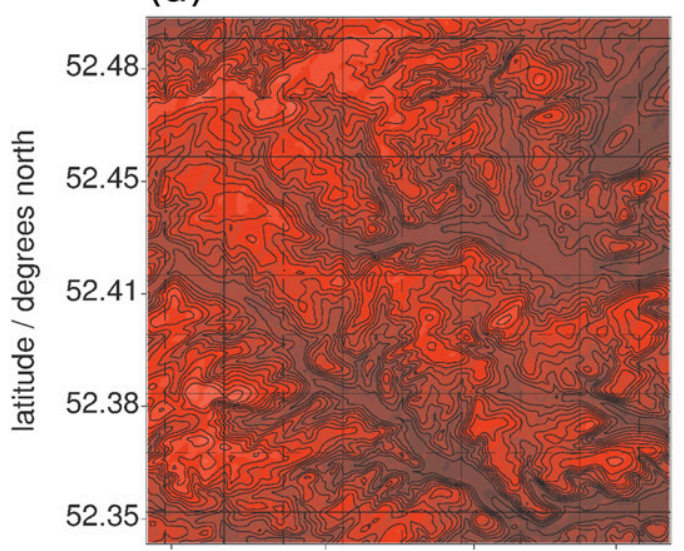

(c) $20090910-18$ UTC

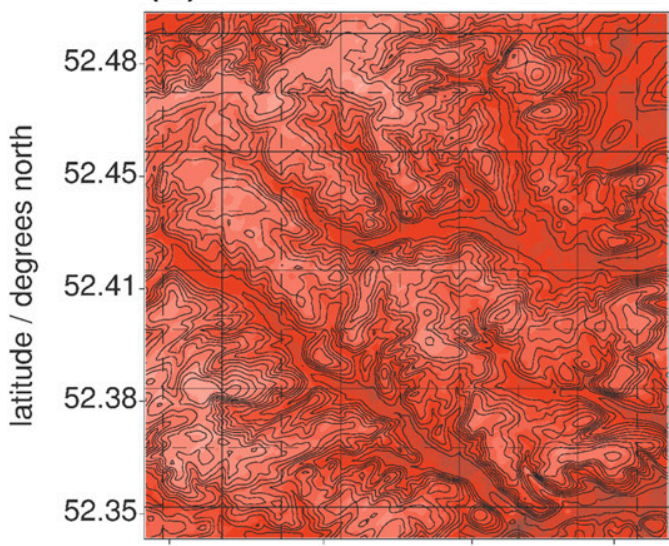

(e) $20090910-22$ UTC

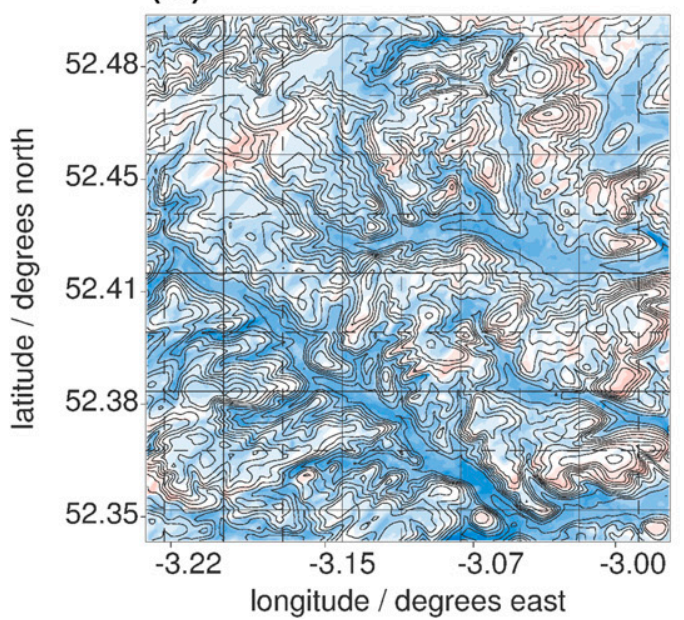

UK4 height correction, valley and hill parameterisations

(b) 20090910 - 14UTC

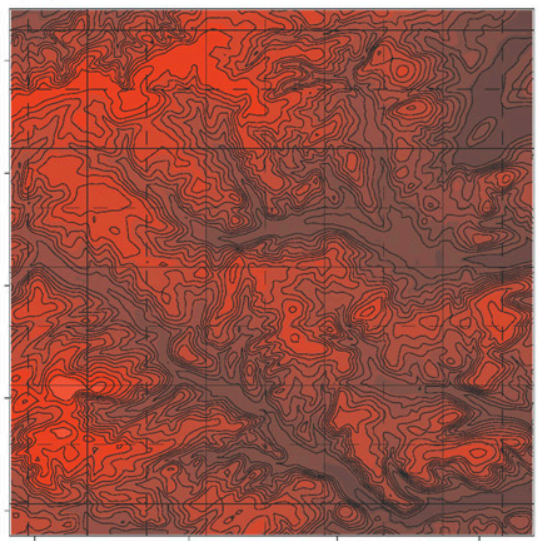

(d) $20090910-18$ UTC

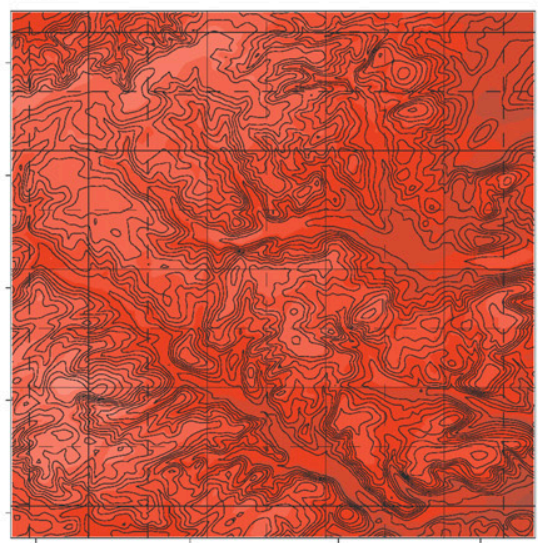

(f) $20090910-22$ UTC

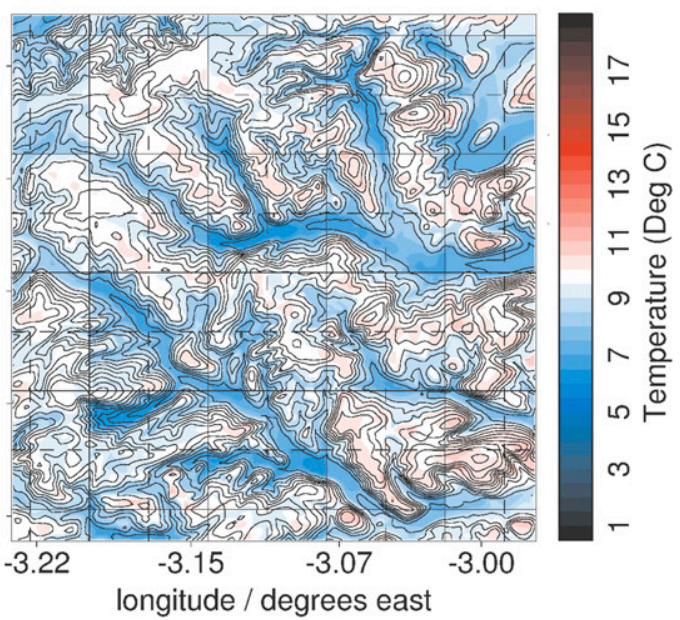

FIG. 8. As in Fig. 7, but at 4-hourly intervals during the evening of 10 Sep 2009, comparing (left) 100-m MetUM and (right) algorithmically downscaled data in pairs of panels. The alternate color scheme to that of Fig. 7 allows convenient comparison on the same scale throughout the diurnal cycle. 
$100 \mathrm{~m}$ model $1.5 \mathrm{~m}$ temperature

(a) 20090911 - 02UTC

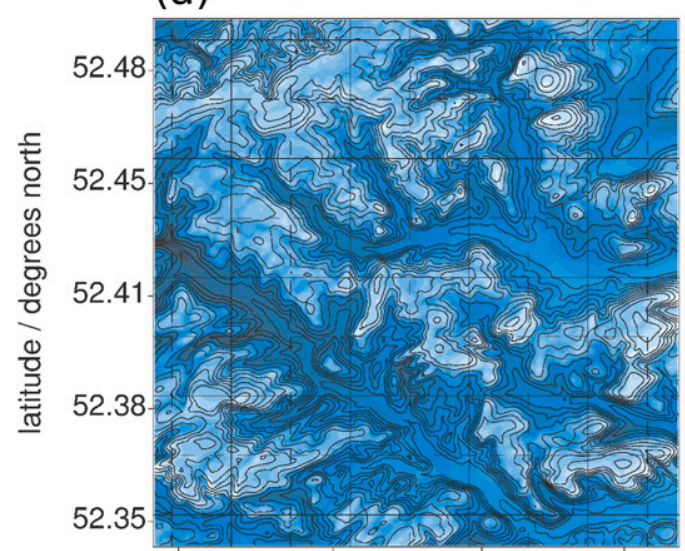

(c) 20090911 - 06UTC

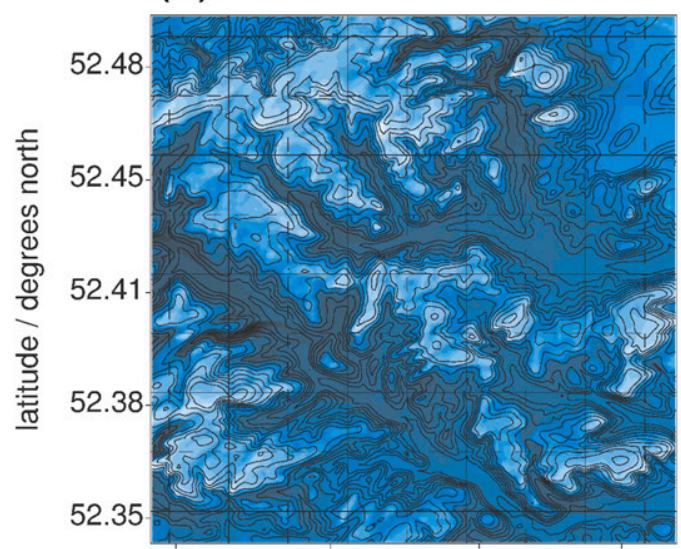

(e) 20090911 - 10UTC

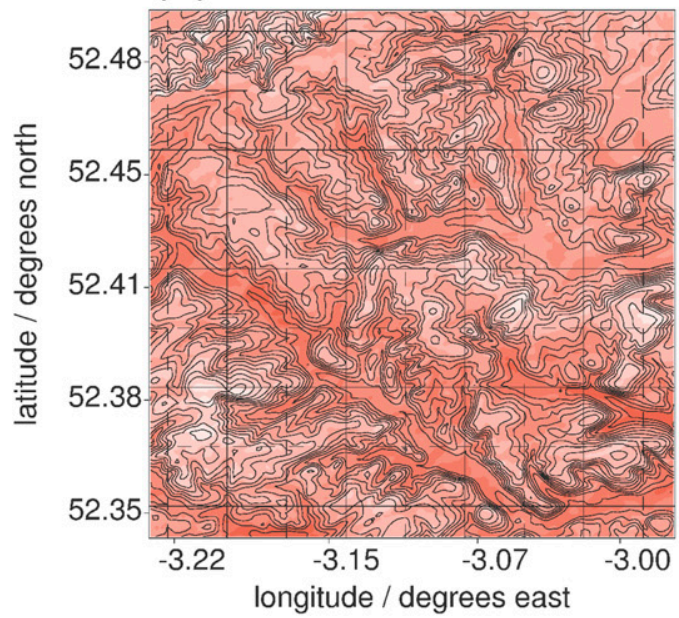

UK4 height correction, valley and hill parameterisations

(b) 20090911 - 02UTC

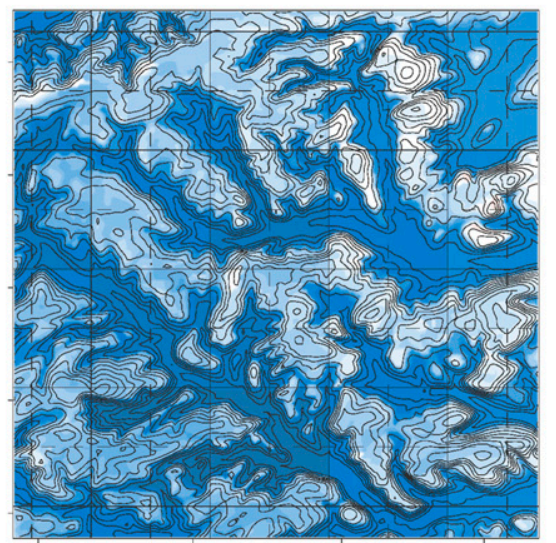

(d) 20090911 - 06UTC

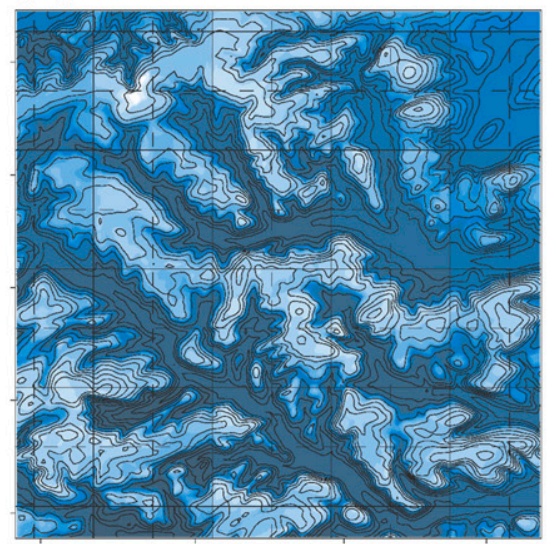

(f) $20090911-10$ UTC

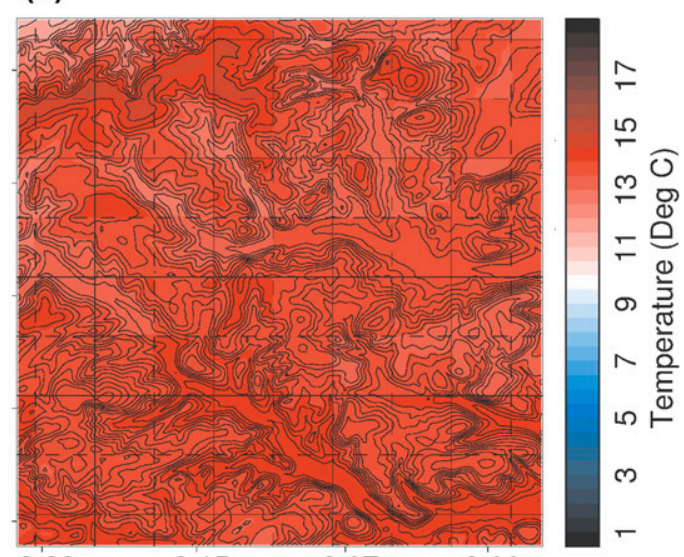

$-3.22$
$-3.07$

longitude / degrees east

FIG. 9. As in Fig. 8, but for the morning hours of 11 Sep 2009. 
TABLE 1. List of cold-pool cases used for example comparison of the downscaling algorithm with observations, listing dates, whether the case was an IOP, whether snow covered the ground, and the relative subjectively evaluated performance over hilltop areas of downscaling using the height correction only, as in the current operational scheme.

\begin{tabular}{cllcc}
\hline \hline Case & Start date & IOP & Snow cover & Current-scheme hill performance \\
\hline 1 & 23 Jun 2009 & Yes & No & Good \\
2 & 10 Sep 2009 & Yes & No & Very poor \\
3 & 7 Jan 2010 & No & Yes & Very poor \\
4 & 4 Mar 2010 & Yes & No & Poor \\
5 & 10 Mar 2010 & Yes & No & Very poor \\
6 & 9 Apr 2010 & No &
\end{tabular}

series over a diurnal cycle for exposed upland sites from COLPEX. The variation of $\theta_{\text {env }}$ is also shown. Stations shown have been selected on the grounds of being representative of the scheme's performance at the majority of sites (during case 1, Springhill was the only upland site that was operational). Cases 1,2 , and 5 originally highlighted the hilltop cold bias. With the addition of the hill parameterization, overnight temperatures in the same cases are now well reproduced. The temperature behavior differs in character on different nights, but the hill parameterization consistently applies a smaller or larger correction as appropriate, giving temperatures sometimes closer to $\theta_{\text {env }}$, sometimes closer to $\theta_{0}$, and improves accuracy. A negative UK4 bias (judging by daytime temperatures) may be responsible for some of the shortfall in Figs. 11d and 11e.

\section{d. Comparison with the full COLPEX dataset}

The downscaling scheme is designed to represent subgrid variability in screen temperature, both in neutral and stable conditions. A concise test of its success is therefore to examine how well it reproduces observed
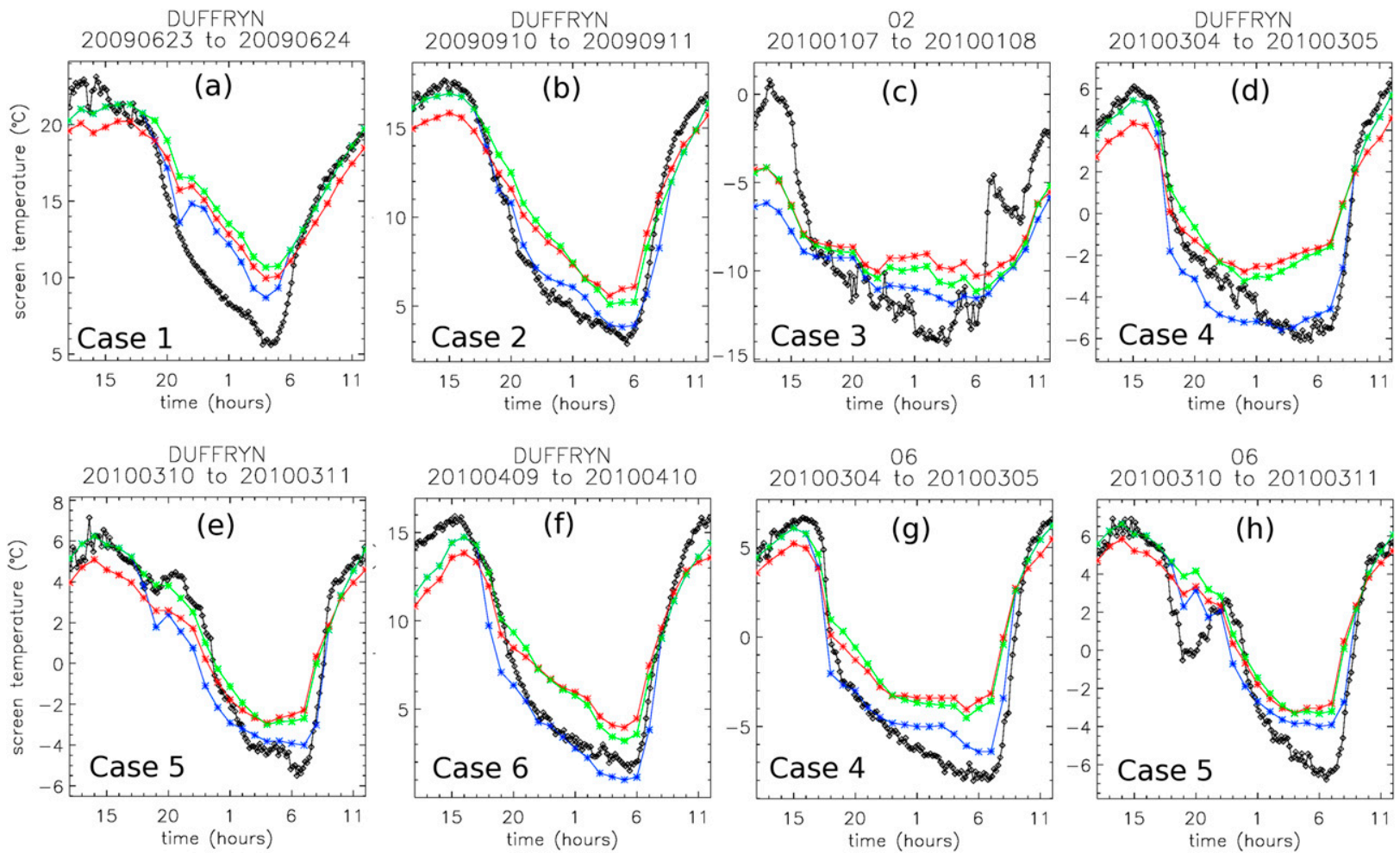

FIG. 10. Time series over one night from midday to midday of screen temperature as observed (black), from raw UK4 (red), as heightcorrected (green), and after the valley parameterization is applied (blue), for the following valley stations and dates: (a) Duffryn for 23-24 Jun 2009, (b) Duffryn for 10-11 Sep 2009, (c) HOBO 2 (Duffryn measurements not available) for 7-8 Jan 2010, (d) Duffryn for 45 Mar 2010, (e) Duffryn for 10-11 Mar 2010, (f) Duffryn for 9-10 Apr 2010, (g) HOBO 6 for 4-5 Mar 2010, and (h) HOBO 6 for 10-11 Mar 2010. 


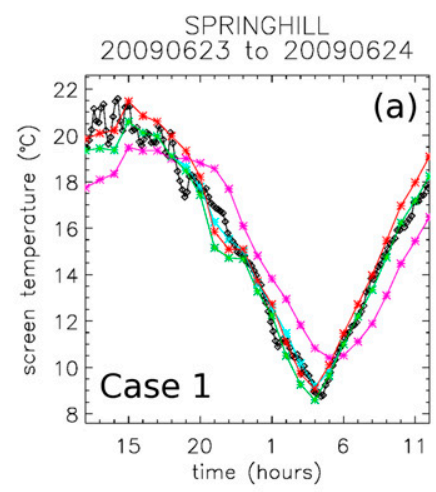

16

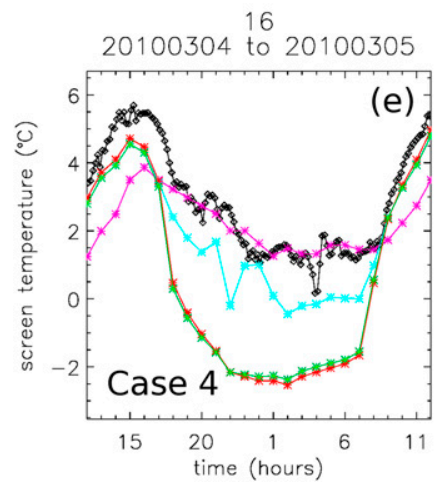

01

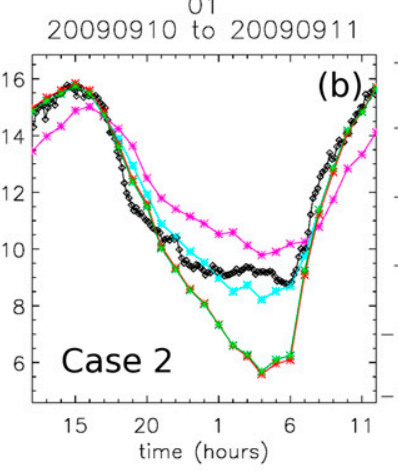

$\mathrm{A} 02$ 20100304 to 20100305

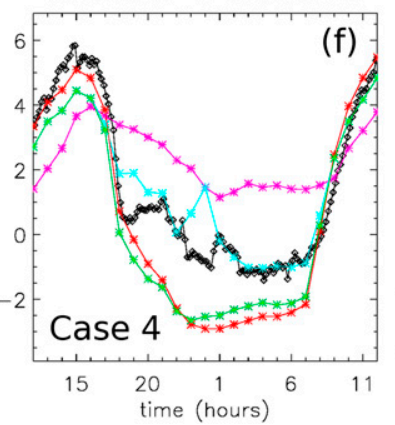

SPRINGHILL 20100107 to 20100108

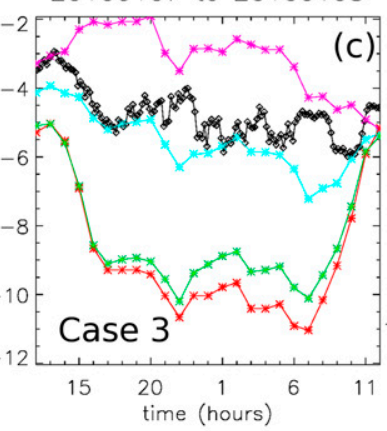

04

20100310 to 20100311

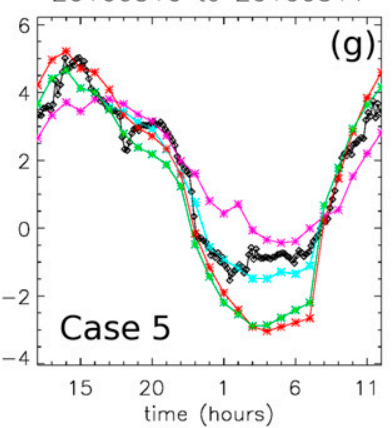

16

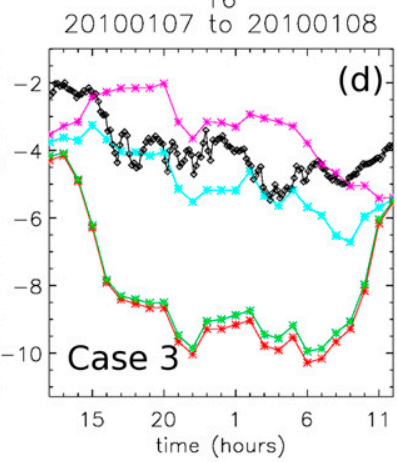

SPRINGHILL 20100409 to 20100410

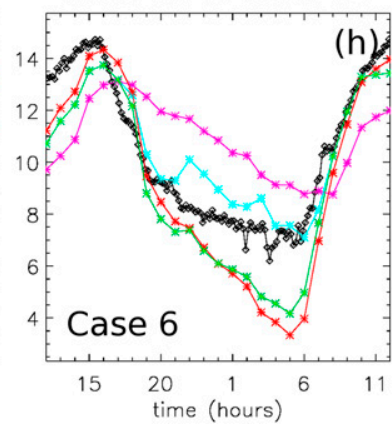

FIG. 11. Similar to Fig. 10, but also depicting temperatures after the hill parameterization is applied (cyan) and temperatures with the hill parameterization upper bound $\theta_{\text {env }}$ (magenta), for the following hilltop stations and dates: (a) Springhill for 23-24 Jun 2009, (b) HOBO 1 for 10-11 Sep 2009, (c) Springhill and (d) HOBO 16 for 7-8 Jan 2010, (e) HOBO 16 and (f) AWS A02 for 4-5 Mar 2010, (g) HOBO 4 for 10-11 Mar 2010, and (h) Springhill for 9-10 Apr 2010.

CAP strength. Sheridan et al. (2014) defined a measure of CAP strength for the Clun Valley as the overnight average of the difference between screen potential temperature at the Springhill mast and that averaged over several valley-bottom stations, $\Delta \theta_{\mathrm{CAP}}$ [we have added the subscript to distinguish from $\Delta \theta$ in Eq. (3)]. Values of $\Delta \theta_{\text {CAP }}$ derived from temperatures downscaled using the 3-component scheme are plotted versus the observed values in Fig. 12d. Values derived from raw UK4 temperatures and temperatures downscaled using the 1-component and 2-component schemes are compared in the same way in Figs. 12a-c, respectively. With successive addition of each of the three components of the scheme, the gradient increases (from roughly zero initially) and the correlation moves closer to the 1:1 line as the representation of CAPs becomes increasingly realistic. Note the substantial positive values in Fig. 12a are related to the conversion to potential temperature without preceding height correction. The slight bulge of points above the 1:1 line in Figs. 12c and 12d likely reflects the need to incorporate some dependence on longwave radiation deficit into the valley parameterization. Apart from any further deficiencies of the scheme, remaining scatter will be due to poor UK4 forecast of cloud or wind, and corresponding impacts on gridbox temperature profile, diagnosed lapse rates, and nondimensional valley depths.

A more exacting test of the scheme involves the computation of RMS errors against the COLPEX observations. Qualitative improvements to an operational scheme should not come at the cost of any detriment to RMS error performance. RMS errors in downscaled temperatures (available as hourly instantaneous data) calculated against the whole COLPEX dataset for all times (using the nearest 10-min average) are reduced from $1.24^{\circ}$ to $1.16^{\circ} \mathrm{C}$ by the height correction compared to raw model data, are essentially unchanged by the valley parameterization, and are further reduced to $1.10^{\circ} \mathrm{C}$ when the hill parameterization is applied. The majority of the instruments used to calculate these values were $\mathrm{HOBOs}$ or mast stations, so an instrument error of $0.15^{\circ} \mathrm{C}$ is for the most part the relevant value when considering the significance of improvements. Note that these statistics cover the entire dataset, while strong CAP cases are relatively rare. Given that the scheme targets large model errors arising during CAPs in particular, when improvements may be much larger than $0.15^{\circ} \mathrm{C}$, we filter the data to focus on the types of 

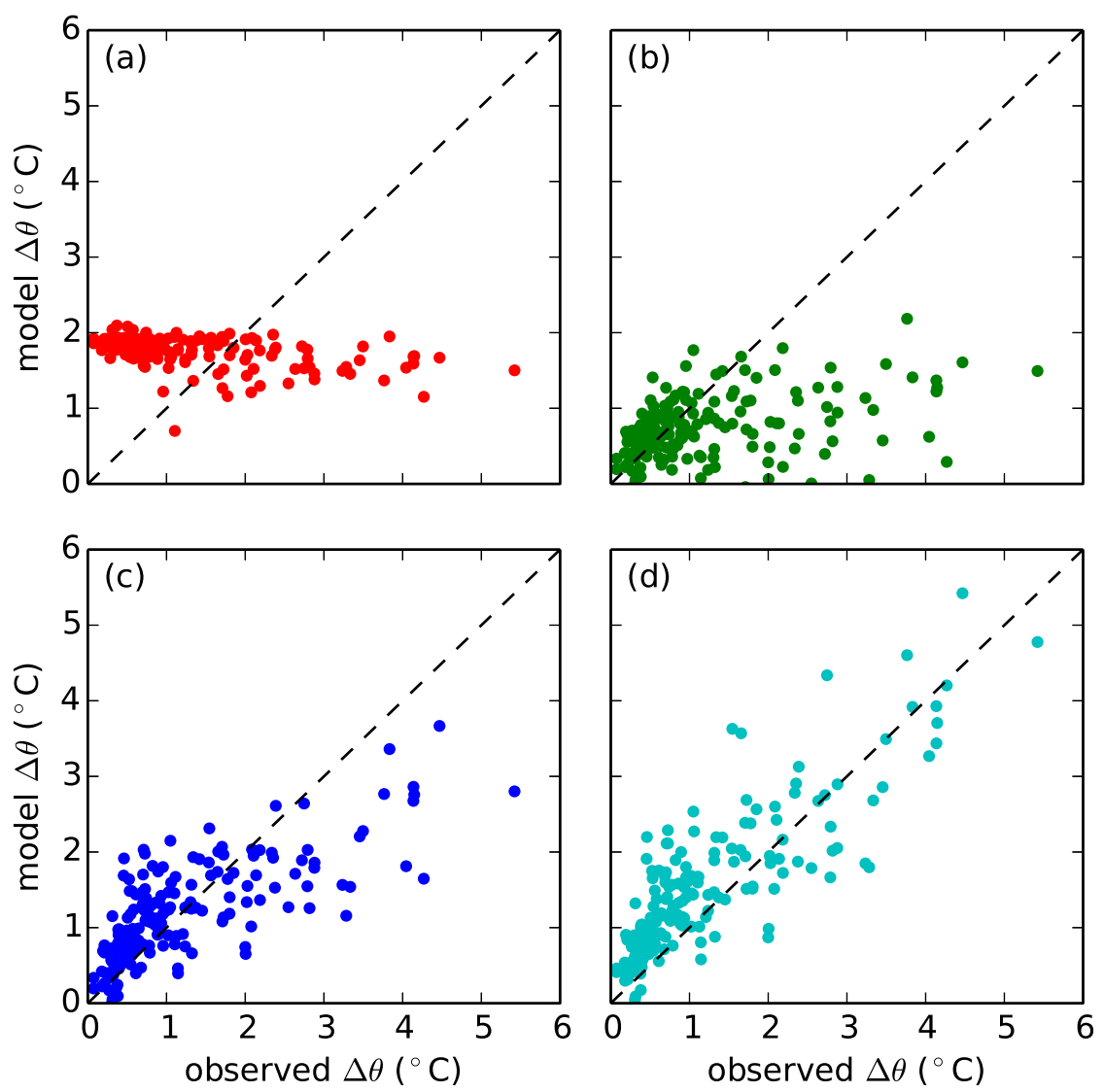

FIG. 12. Comparison (with observations) of CAP strength as defined by Sheridan et al. (2014) (see text) as derived from (a) raw UK4 screen potential temperature and from potential temperatures downscaled using the (b) 1-c, (c) 2-c, and (d) 3-c schemes, for all nights during the COLPEX dataset with sufficient data.

cases and locations most affected by cold-air pooling (nighttime, stable conditions, and hilltop or valleybottom locations). The two tables discussed in the following are included to allow examination of the impact of individual filters from this combination.

RMS errors comparing downscaling performance before and after the valley parameterization is applied (and raw UK4 performance) are compiled in Table 2. Rows and columns indicate partial filtering of the dataset to focus on a defined nocturnal period (times between 2200 and 0400 UTC inclusive), valley-bottom locations (Duffryn, Burfield, HOBOs 2, 6, 7, 13, and 22, and AWSs A01, A03, A05, A06, A07, A08, and A09; Sheridan et al. 2014), or strong cold-pool cases [according to the value of $\Delta \theta_{\mathrm{CAP}}$ determined by Sheridan et al. (2014)], and combinations of any two of these filters. These show a greater impact as would be expected (for comparison, the impact of the height correction for the same categories is generally an improvement of less than $0.05^{\circ} \mathrm{C}$ ). Combining all three filters gives a set of cases for which RMS errors are reduced from $2.30^{\circ}$ to $1.63^{\circ} \mathrm{C}$ by application of the valley parameterization.

RMS errors comparing downscaling performance before and after the hill parameterization is applied (and raw UK4 performance), with the same filter combinations except this time focusing on exposed upland locations in place of valley-bottom sites (Springhill, HOBOs 1, 4, 8, 9, 12, 16, and 17, and AWSs A02 and A0; Sheridan et al. 2014) are compiled in Table 3 and similarly show a greater impact than with the dataset as a whole. Combining all three filters gives a set of cases for which the hill parameterization reduces RMS errors even more, from $1.55^{\circ}$ to $0.89^{\circ} \mathrm{C}$. Removal of aforementioned UK4 biases could improve this even further.

While the reductions in RMS errors quoted may seem small in terms of absolute numbers, the qualitative impact of the scheme should be emphasized. This is greatest in the strongest CAP cases. For instance, the qualitative improvement in each of cases 1-6 is comparable, and can be judged by contrasting Fig. $6 a$ and Fig. $7 b$. No subgrid 
TABLE 2. RMS errors in downscaled temperatures vs COLPEX observations using raw UK4 data, or height correction only (1-c), or also applying the valley parameterization (2-c, representing the current operational scheme), for different combinations of filters that each confine analysis to nighttime (2200-0400 UTC), valley-bottom stations, or moderate-to-strong cold-pool cases $\left(\Delta \theta_{\mathrm{CAP}} \geq 2^{\circ} \mathrm{C}\right)$. The diagonal corresponds to a single filter, and off-diagonal elements represent a combination of the two filters in the corresponding row/ column. For each filter combination, three RMSE values are listed, one for each model/downscaled dataset (raw, 1-c, and 2-c).

\begin{tabular}{|c|c|c|c|c|c|c|c|c|c|}
\hline & \multicolumn{3}{|c|}{ Valley } & \multicolumn{3}{|c|}{ Nighttime } & \multicolumn{3}{|c|}{$\Delta \theta_{\mathrm{CAP}} \geq 2^{\circ} \mathrm{C}$} \\
\hline & Raw & $1-\mathrm{c}$ & $2-c$ & Raw & $1-\mathrm{c}$ & $2-c$ & Raw & $1-c$ & $2-c$ \\
\hline Valley & 1.41 & 1.24 & 1.23 & 1.46 & 1.42 & 1.30 & 1.89 & 1.88 & 1.41 \\
\hline Nighttime & & & & 1.29 & 1.25 & 1.24 & 1.72 & 1.78 & 1.58 \\
\hline$\Delta \theta_{\mathrm{CAP}} \geq 2^{\circ} \mathrm{C}$ & & & & & & & 1.53 & 1.52 & 1.41 \\
\hline
\end{tabular}

variation exists in Fig. 6a, while substantial, fairly realistic subgrid CAPs are present in Fig. 7b. Also, RMS error reductions are greatest in extreme cases. For instance, confining to where $\Delta \theta_{\mathrm{CAP}}>4^{\circ} \mathrm{C}$ (only seven cases), RMS errors overnight are reduced from $2.36^{\circ}$ to $0.95^{\circ} \mathrm{C}$ at upland sites before and after application of the hill parameterization.

It is noteworthy that, despite the obvious qualitative improvements due to the valley parameterization, valley-bottom sites still give rise to higher RMS errors than hilltop sites. This presumably reflects the more dramatic local temperature gradients in the lower reaches of valleys, and the relative simplicity of the valley parameterization, which cannot capture local dynamical effects that influence the precise temperature variation along the valley floor. Attempts to incorporate aspects of decoupled valley internal flow dynamics might lead to further improvement.

\section{Discussion}

The improvements in local temperature modeling offered by the downscaling scheme compared to raw mesoscale model data having already been shown, this section summarizes how the scheme could be improved or extended to be more useful.

One shortcoming of the valley parameterization is the dependence purely on a diagnosed nondimensional valley depth $(\bar{N} H / \bar{U})$. Stable/low wind conditions (large $\bar{N} H / \bar{U}$ ) may occur in the driving-model grid box when skies are relatively cloudy and cold pools are in fact unlikely to intensify; similarly, stable profiles occurring during the day (e.g., over a snow surface) may lead to large $\bar{N} H / \bar{U}$, when net radiative flux is in fact downward and cold pools are unlikely to persist. Incorporating sensitivity to net nocturnal radiative surface cooling would improve this.

Comparison with COLPEX observations and 100-mresolution simulations demonstrates that localized cold features within valley bottoms are difficult to reproduce with precision, and it is possible that the calculation of local valley depth $H$ is currently too simple. The determination of $H$ relative to the mean terrain within a 4-km box implies an assumption about the scale selectivity of cold-pool formation. In fact, cold pools may form in very small terrain concavities or equally in broad mountain basins. Of course, a 4-km scale coincides with the driving NWP-model grid length, and valley features on a larger scale than this should start to become resolved, with cold-pooling processes beginning to be represented explicitly in the driving model. However, it is unclear at what point valleys and cold-pooling processes are effectively resolved from this point of view [almost certainly not before they are more than several grid points wide; even then, coarse vertical resolution may limit representativeness (Vosper et al. 2013)]. The effect of this scale selectivity in $H$ could potentially be implicated in overestimation of CAP temperatures at two stations in broader valley areas (HOBOs 6 and 7). However, the additional effect of downvalley terrain constriction appeared to be an even bigger factor in overestimation of temperature. A formulation more

TABLE 3. RMS errors in raw UK4 or downscaled temperatures vs COLPEX observations using the scheme with (3-c) and without (2-c) the hill parameterization, for different combinations of filters, confining analysis to nighttime (2200-0400 UTC), exposed upland stations, or moderate-to-strong cold-pool cases $\left(\Delta \theta_{\mathrm{CAP}} \geq 2^{\circ} \mathrm{C}\right)$ as in Table 2.

\begin{tabular}{|c|c|c|c|c|c|c|c|c|c|}
\hline & \multicolumn{3}{|c|}{ Upland } & \multicolumn{3}{|c|}{ Nighttime } & \multicolumn{3}{|c|}{$\Delta \theta_{\mathrm{CAP}} \geq 2^{\circ} \mathrm{C}$} \\
\hline & Raw & $2-c$ & $3-c$ & Raw & $2-c$ & $3-c$ & Raw & $2-c$ & $3-c$ \\
\hline Upland & 1.19 & 1.17 & 0.97 & 1.27 & 1.25 & 0.92 & 1.35 & 1.34 & 0.94 \\
\hline Nighttime & & & & 1.29 & 1.24 & 1.14 & 1.72 & 1.58 & 1.40 \\
\hline$\Delta \theta_{\mathrm{CAP}} \geq 2^{\circ} \mathrm{C}$ & & & & & & & 1.53 & 1.41 & 1.30 \\
\hline
\end{tabular}


sensitive to terrain scale/shape and valley flow dynamics may improve the scheme's discernment of the coldest valley locations. When applying the scheme with higherresolution driving models (such as the $1.5-\mathrm{km}$ resolution U.K. model, the UKV, that is currently operational at the Met Office), the use of a different mean terrain scale could be considered.

A related concern is that the valley parameterization will only apply cooling below the local mean terrain elevation, and the hill parameterization can only apply warming above this elevation; the screen temperature where the terrain intersects the mean surface is always equal to the raw value from the driving model. This overconstrains the profile of vertical variation of screen temperature within the terrain. Comparisons with midslope stations during strong cold pools (not shown) reveal a strong cold bias, indicating that the present configuration overestimates the depth (or equally, width) of cold pools. A similar bias was revealed for a 100-mresolution MetUM simulation of a COLPEX case study by Vosper et al. (2014), reflecting the similarity in morphology between 100-m-resolution MetUM-simulated and algorithmically downscaled screen temperature patterns found here (Fig. 7). The misplacement of the coldpool "top" in this way will lead to a double penalty; with the scheme cooling locations it should in fact warm. A method to adapt the height at which the scheme makes the transition from valley to hill parameterization depending on the conditions (e.g., diagnosis of a dividing streamline on the basis of the gridbox profile) could release this constraint and improve realism.

The suggestion in the literature that the exponent $n$ in one of the hill parameterization's central formulas (defining the shape of the internal boundary layer that is assumed to form adjacent to the hilltop surface) depends on certain conditions of meteorology and terrain seems borne out in this work. The assumption of a constant value, though effective here, may need to be revisited. Meanwhile, poor performance of the valley parameterization during a case with lying snow underlines the likely importance of surface properties in determining temperature patterns. While this may be in part due to deficiencies of the driving model in reproducing the impacts of lying snow on surface fluxes and the gridbox screen temperature, the variation of temperature at subgrid scales is also likely to depend significantly on surface properties, no account of which is made in the downscaling scheme. For instance, Kiefer and Zhong (2013), Kiefer and Zhong (2015), and Gustavsson et al. (1998) also demonstrate strong impacts (not necessarily in the same sense) on valley-bottom temperatures when comparing cold pools in forested and unforested valleys.
A number of other avenues for future algorithm improvement remain open. Adaptability to other locations could be improved if the scheme could accommodate the impacts of changes in latitude (solar elevation angle, shading, radiative balance), surface properties (e.g., snow, vegetation cover), and valley-base elevation (e.g., elevated sinkholes) on subgrid variability. A large part of this might be resolved through sensitivity to net radiative flux discussed above, strengthening the argument for inclusion of this. Significant variation in geography, specifically valley scale and aspect ratio, present a challenge to the scheme. In larger terrain, factors such as gravity waves and extensive downslope winds (Sheridan and Vosper 2014), and strong katabatic flows become more important during cold-pool episodes, nonlinear dynamical effects that are difficult to parameterize. When model height errors are very large (e.g., steep exposed peaks), certain assumptions in the hill parameterization, such as those concerning the representativeness of its "lower bound," may become inappropriate [Pepin and Seidel (2005) highlight the strong correlation between near-surface mountaintop temperatures and free-air temperatures], and this requires investigation.

Using the scheme in locations that are not covered by high-resolution limited-area models would require the use of a coarser-resolution driving model. The performance of the scheme with driving-model grid spacing of greater than $4 \mathrm{~km}$ has not yet been investigated.

Given the link between fog formation and low temperatures, downscaled temperature fields offer a potential route to improved visibility forecasting in complex terrain where coarse mesoscale models underpredict the intensity of temperature minima. Experimentation in coupling the scheme to a visibility calculation is under way.

While the scheme offers a deterministic forecast of temperature at very high resolution, another useful approach would be to use the scheme to express variability more generally within a grid box or neighborhood of grid boxes, perhaps as part of an ensemble system, as a function of elevation, for instance.

In principle, the scheme could also be applied to climate model projections (climate simulations at resolutions comparable to current NWP weather forecasts have recently started to become available; Kendon et al. 2014; Zhang et al. 2016). Elevation-dependent warming (EDW) of climate is a current focus of climate change research (Pepin et al. 2015); the mechanisms underlying the scheme described here, reflecting hilltop temperatures coupled to, and valley-bottom temperatures decoupled from, airmass temperature are consistent with EDW trends (assuming an airmass warming trend) found by Pepin et al. (2015). 
The downscaling algorithm can be used as a tool to support research. Its relative simplicity makes its performance in a given case straightforward to explain in terms of the processes it is formulated to represent and the inputs it relies on. It may thus be useful as part of a "hierarchy" of models (e.g., alongside more complex results from dynamical downscaling) in understanding problems such as fog formation. The latter is the focus of a new campaign, the Local and Nonlocal Fog Experiment (LANFEX) recently completed in Shropshire and Bedfordshire, England (Price et al. 2018).

\section{Conclusions}

A scheme for postprocessing data from coarseresolution mesoscale models to produce downscaled screen temperature forecasts has been applied to locations monitored during the COLPEX field campaign in Shropshire. The strongest impact comes from two components of the scheme: a "valley parameterization" (designed to improve temperature forecasts in stable conditions in valleys) and a "hill parameterization" (designed to improve forecasts over hilltops in stable conditions). Operating in addition to a basic height correction (Sheridan et al. 2010), these produce realistic forecast temperature patterns during valley cold-air pools when compared with a very high resolution dynamical downscaling model and COLPEX observations. RMS errors were consequently reduced at the COLPEX sites. The height correction and valley parameterization have already been implemented operationally in Met Office postprocessing, while the hill parameterization is a new component. For exposed upland sites during nocturnal cold-pool periods, RMS errors are reduced from $1.55^{\circ}$ to $0.89^{\circ} \mathrm{C}$ with the addition of the hill parameterization (the valley parameterization has a comparable impact).

The ability of the downscaling scheme to reproduce qualitative CAP temperature patterns is attributed to the design of the parameterizations, which takes into account existing research results on CAP formation and physical reasoning. The valley parameterization represents the influence of sheltering processes on valley cooling through a nondimensional valley depth diagnosed from coarse mesoscale forecast model data. The hill parameterization reflects advection and adjustment processes over hilltops, which have large effects on nights when radiative cooling of the surface is strong. The two parameterizations combine to reproduce the large hillvalley temperature contrasts associated with CAPs.

A number of possible future scheme improvements/ adaptations were discussed: sensitivity of the valley parameterization to the strength of nocturnal radiative cooling, a diagnosis of CAP depth to better qualitatively represent temperature patterns on different nights, consideration of partially resolved CAPs (e.g., subgrid drainage mechanics), adaptability to different surface types (including snow cover) and latitudes, and ensuring the hill parameterization performance is robust in steep terrain where NWP model height errors may be large. The scheme could also be extended to reprocess forecast visibilities, which are strongly influenced by temperature.

Acknowledgments. We gratefully acknowledge the extensive efforts of the team of scientists involved in taking measurements and managing observational data from the COLPEX campaign, principally those workers at Cardington MRU (Met Office) and Bradley JemmettSmith (University of Leeds). Met Office interns Tim Slater and Charles Field performed initial investigations into the performance of the UK4 model and the operational downscaling scheme, which was very helpful to this work. John Hughes (University of Leeds) performed 100-m model simulations as part of the COLPEX campaign and is thanked for supplying related data and advice. We thank the reviewers for suggestions that have improved the clarity and focus of the paper.

\section{APPENDIX A}

\section{Description of Leeside Descent Parameterization}

Here, the treatment of leeside descent and acceleration, which tends to warm the leeward shoulder of exposed terrain in CAP situations, is described. If the same relative acceleration acts throughout the near-surface layer above a given point and is simply assumed to thin the flow adiabatically, compressing isentropes near the surface according to continuity, then the associated modification of temperature is given, for a linear potential temperature profile, by $\theta_{\text {mod }}-\theta=\varepsilon\left(\theta-\theta_{0}\right)\left[\left(u_{\text {mod,sc }} / u_{\mathrm{sc}}\right)-1\right]$ with $\varepsilon=1$, where $\theta_{\text {mod }}$ is the potential temperature with modification due to leeside descent (the modification is further capped so that $\theta_{\text {mod }}$ is not permitted to exceed $\theta_{\text {env }}$ ) and $u_{\text {mod,sc }}$ and $u_{\mathrm{sc}}$ are the screen wind speed respectively with and without modification by leeside descent. This, however, was found to frequently produce excessively high temperatures. In practice $\varepsilon=\left(\theta_{\mathrm{env}}-\theta\right) /\left(\theta_{\mathrm{env}}-\theta_{0}\right)$ was used, which ensures that the leeside modification is only significant when significant adjustment according to Eq. (3) has occurred at screen level. To calculate $u_{\text {mod,sc }}$, first $\bar{N}$ and $\bar{U}$ are used to derive a gravity wave horizontal wavelength $\lambda=2 \pi \bar{U} / \bar{N}$. The initial screen-level estimate of wind speed $u_{\mathrm{sc}}$ is derived from $u_{*}$ assuming logarithmic behavior. A mean of the relative terrain height downwind within one wavelength $H_{\lambda}$ is normalized 
relative to the highest local protrusion through the mean surface $H_{\max }$ to provide a gauge of likely descent. This is multiplied by the difference between $\bar{U}$ and $u_{\mathrm{sc}}$ and added to $u_{\mathrm{sc}}$ to give $u_{\text {mod,sc }}$. Where terrain drops below the mean surface, the mean surface height is substituted in the calculation of $H_{\lambda}$, to reflect the pseudoterrain surface supplied by any cold pool. $H_{\max }$ is determined within the domain for the idealized tests, within one-half of a grid box to either side of the POI when downscaling NWP data. The cap that was applied to $U_{p}$, discussed in section $3 \mathrm{c}$, ensures that there is always a significant difference between $\bar{U}$ and $u_{\mathrm{sc}}$ (without this, the leeside modification was found at times to be far too weak).

\section{APPENDIX B}

\section{Adapting the Algorithm for Application to NWP Data}

A number of features were changed or had to be adapted when applying the downscaling algorithm in comparison with observational data and real-case MetUM simulations. Calculation of $H_{\max }$ involved searching terrain along the wind direction within $2 \mathrm{~km}$ upwind and downwind of the POI. As an attempt to move the waveinduced warming area farther to leeward in more nonlinear situations, both upwind terrain that is higher than the POI and downwind terrain that is lower were taken into account in the descent parameterization, weighting the upwind terrain more when a nondimensional hill height based on the along-wind terrain variation was large, and vice versa. Since the local mean surface and the gridbox surface do not always coincide, the valley parameterization is taken to act for POIs below the mean surface, the hill parameterization for those above. For the latter, the section of the driving profile below the maximum terrain height in a POI-centered 4-km box was linearly dilated or compressed so its base coincided with the mean surface. The direction for determination of along-wind terrain was diagnosed from the driving profile at the height of the POI. An "exposure" factor to reflect the impact on the speed of adjustment of the steepness of protrusion of upwind terrain through the mean surface was applied in the idealized tests but was subsequently neglected. In fact, a lower limit of $300 \mathrm{~m}$ restricting the value of $x_{\mathrm{ifc}}$ was found to be necessary to prevent sharp warming of shallow protrusions, perhaps because of the shallower slopes involved. Last, changing the exponent $n$ from 1 to 0.5 was found to be necessary. Garratt and Ryan (1989) compared values of $n$ obtained from different datasets, finding that $n=2$ for the dataset they presented, involving offshore flow (i.e., rougher to smoother surface), where IBL growth was dominated by turbulent flux. Other datasets for which radiative cooling was more important were shown to display the opposite profile curvature $(n<1)$, with results from two studies implying $n=0.5$. The meteorological conditions accompanying the cold-pool cases during COLPEX suggest that the latter case is more relevant, whereas the shallow stable layers observed over hilltops during the campaign (see, e.g., Figs. 4c and 4d of Sheridan et al. 2014) conform roughly to the corresponding parabolic shape. It is also notable that the BLASIUS simulations that were well reproduced using $n=1$ neglect atmospheric radiative flux divergence terms (Vosper and Brown 2008). No alteration was made to the leeside descent component of the scheme to reflect this change in $n$. Last, the roughness length of $0.1 \mathrm{~m}$ was replaced by the UK4 gridbox roughness value.

\section{REFERENCES}

Adler, B., C. D. Whiteman, S. W. Hoch, M. Lehner, and N. Kalthoff, 2012: Warm-air intrusions in Arizona's Meteor Crater. J. Appl. Meteor. Climatol., 51, 1010-1025, https://doi.org/ 10.1175/JAMC-D-11-0158.1.

Allen, T., and A. R. Brown, 2006: Modelling of turbulent form drag in convective conditions. Bound.-Layer Meteor., 118, 421-429, https://doi.org/10.1007/s10546-005-9002-z.

Bodine, D., P. M. Klein, S. C. Arms, and A. Shapiro, 2009: Variability of surface air temperature over gently sloped terrain. J. Appl. Meteor. Climatol., 48, 1117-1141, https://doi.org/ 10.1175/2009JAMC1933.1.

Bogren, J., and T. Gustavsson, 1989: Modelling of local climate for prediction of road slipperiness. Phys. Geogr., 10, 147-164.

Bornemann, J., H. W. Lean, C. A. Wilson, and P. A. Clark, 2005: A new high resolution model for the UK. Extended Abstracts, WNS05 Proc., Toulouse, France, Météo-France, http:// www.meteo.fr/cic/wsn05/DVD/resumes/longs/6.08-79.pdf.

Boutle, I. A., A. Finnenkoetter, A. P. Lock, and H. Wells, 2016: The London Model: Forecasting fog at $333 \mathrm{~m}$ resolution. Quart. J. Roy. Meteor. Soc., 142, 360-371, https://doi.org/ 10.1002/qj.2656.

Brasseur, O., 2001: Development and application of a physical approach to estimating wind gusts. Mon. Wea. Rev., 129, 5-25, https://doi.org/ 10.1175/1520-0493(2001)129<0005:DAAOAP $>2.0 . C O ; 2$.

Brown, A. R., and N. Wood, 2003: Properties and parametrization of the stable boundary layer over moderate topography. J. Atmos. Sci., 60, 2797-2808, https://doi.org/10.1175/1520-0469(2003)060<2797: PAPOTS $>2.0 . \mathrm{CO} ; 2$

Chemel, C., G. Arduini, C. Staquet, Y. Largeron, D. Legain, D. Tzanos, and A. Paci, 2016: Valley heat deficit as a bulk measure of wintertime particulate air pollution in the Arve River Valley. Atmos. Environ., 128, 208-215, https://doi.org/ 10.1016/j.atmosenv.2015.12.058

Chung, U., H. Seo, K. H. Hwang, J. Hwang, J. Choi, J. T. Lee, and J. I. Yum, 2006: Minimum temperature mapping over complex terrain by estimating cold air accumulation potential. Agric. For. Meteor., 137, 15-24, https://doi.org/ 10.1016/j.agrformet.2005.12.011.

Clements, C. B., C. D. Whiteman, and J. D. Horel, 2003: Cold-airpool structure and evolution in a mountain basin: Peter Sinks, Utah. J. Appl. Meteor., 42, 752-768, https://doi.org/10.1175/ 1520-0450(2003)042<0752:CSAEIA > 2.0.CO;2. 
Davies, T., M. J. P. Cullen, A. J. Malcolm, M. H. Mawson, A. Staniforth, A. A. White, and N. Wood, 2005: A new dynamical core for the Met Office's global and regional modelling of the atmosphere. Quart. J. Roy. Meteor. Soc., 131, 1759-1782, https://doi.org/10.1256/qj.04.101.

Della-Marta, P. M., H. Mathis, C. Frei, M. A. Liniger, J. Kleinn, and C. Appenzeller, 2009: The return period of wind storms over Europe. Int. J. Climatol., 29, 437-459, https://doi.org/ 10.1002/joc.1794.

Gal-Chen, T., and R. Somerville, 1975: On the use of a coordinate transformation for the solution of the Navier-Stokes equations. J. Comput. Phys., 17, 209-228, https://doi.org/10.1016/ 0021-9991(75)90037-6.

Garratt, J. R., 1987: The stably stratified internal boundary layer for steady and diurnally varying offshore flow. Bound.-Layer Meteor., 38, 369-394, https://doi.org/10.1007/BF00120853.

—_ and B. F. Ryan, 1989: The structure of the stably stratified internal boundary layer in offshore flow over the sea. Bound.-Layer Meteor., 47, 17-40, https://doi.org/10.1007/ BF00122320.

Gustavsson, T., M. Karlsson, J. Bogren, and S. Lindqvist, 1998: Development of temperature patterns during clear nights. J. Appl. Meteor., 37, 559-571, https://doi.org/10.1175/ 1520-0450(1998)037<0559:DOTPDC > 2.0.CO;2.

Hofer, M., B. Marzeion, and T. Molg, 2015: A statistical downscaling method for daily air temperature in data-sparse, glaciated mountain environments. Geosci. Model Dev., 8, 579-593, https://doi.org/10.5194/gmd-8-579-2015.

Holden, Z. A., J. T. Abatzoglou, C. H. Luce, and L. S. Baggett, 2011: Empirical downscaling of daily minimum air temperature at very fine resolutions in complex terrain. Agric. For. Meteor., 151, 1066-1073, https://doi.org/10.1016/j.agrformet.2011.03.011.

Hughes, J. K., A. N. Ross, S. B. Vosper, A. P. Lock, and B. C. Jemmett-Smith, 2015: Assessment of valley cold pools and clouds in a very high-resolution numerical weather prediction model. Geosci. Model Dev., 8, 3105-3117, https://doi.org/ 10.5194/gmd-8-3105-2015.

Iijima, Y., and M. Shinoda, 2000: Seasonal changes in the coldair pool formation in a subalpine hollow, central Japan. Int. J. Climatol., 20, 1471-1483, https://doi.org/10.1002/10970088(200010)20:12<1471::AID-JOC554>3.0.CO;2-6.

Jemmett-Smith, B., 2014: Cold air pools over complex terrain. Ph.D. thesis, School of Earth and Environment, University of Leeds, 243 pp., http://etheses.whiterose.ac.uk/6414/1/ BCJemmettSmith_Thesis_20140429.pdf.

Juga, I., P. Nurmi, and M. Hippi, 2013: Statistical modelling of wintertime road surface friction. Meteor. Appl., 20, 318-329, https://doi.org/10.1002/met.1285.

Kendon, E. J., N. M. Roberts, H. J. Fowler, M. J. Roberts, S. C. Chan, and C. A. Senior, 2014: Heavier summer downpours with climate change revealed by weather forecast resolution model. Nat. Climate Change, 4, 570-576, https://doi.org/ 10.1038/nclimate2258.

Kiefer, M. T., and S. Zhong, 2013: The effect of sidewall forest canopies on the formation of cold-air pools: A numerical study. J. Geophys. Res. Atmos., 118, 5965-5978, https://doi.org/ 10.1002/jgrd.50509.

$\longrightarrow$, and -2015 : The role of forest cover and valley geometry in cold-air pool evolution. J. Geophys. Res. Atmos., 120, 8693 8711, https://doi.org/10.1002/2014JD022998.

Krsmanc, R., A. S. Slak, and J. Demsar, 2013: Statistical approach for forecasting road surface temperature. Meteor. Appl., 20, 439-446, https://doi.org/10.1002/met.1305.
Lareau, N., E. Crosman, C. D. Whiteman, J. D. Horel, S. W. Hoch, W. O. J. Brown, and T. W. Horst, 2013: The Persistent ColdAir Pool Study. Bull. Amer. Meteor. Soc., 94, 51-63, https:// doi.org/10.1175/BAMS-D-11-00255.1.

Largeron, Y., and C. Staquet, 2016a: The atmospheric boundary layer during wintertime persistent inversions in the Grenoble valleys. Front. Earth Sci., 4, 70, https://doi.org/10.3389/ feart.2016.00070.

$\longrightarrow$, and _ 2016b: Persistent inversion dynamics and wintertime PM10 air pollution in Alpine valleys. Atmos. Environ., 135, 92-108, https://doi.org/10.1016/j.atmosenv.2016.03.045.

Lehner, M., R. Rotunno, and C. D. Whiteman, 2016a: Flow regimes over a basin induced by upstream katabatic flows-An idealized modeling study. J. Atmos. Sci., 73, 3821-3842, https:// doi.org/10.1175/JAS-D-16-0114.1.

_ , and Coauthors, 2016b: The METCRAX II field experiment: A study of downslope windstorm-type flows in Arizona's Meteor Crater. Bull. Amer. Meteor. Soc., 97, 217-235, https:// doi.org/10.1175/BAMS-D-14-00238.1.

Mahrt, L., J. Sun, S. P. Oncley, and T. W. Horst, 2014: Transient cold air drainage down a shallow valley. J. Atmos. Sci., 71, 2534-2544, https://doi.org/10.1175/JAS-D-14-0010.1.

Nieuwstadt, F. T. M., and H. Tennekes, 1981: A rate equation for the nocturnal boundary-layer height. J. Atmos. Sci., 38, 1418-1428, https://doi.org/10.1175/1520-0469(1981)038<1418: AREFTN $>2.0 . \mathrm{CO} ; 2$.

Panofsky, H. A., and J. A. Dutton, 1984: Atmospheric Turbulence: Models and Methods for Engineering Applications. John Wiley and Sons, $397 \mathrm{pp}$.

Pepin, N., and J. R. Norris, 2005: An examination of the differences between surface and free-air temperature trend at highelevation sites: Relationships with cloud cover, snow cover, and wind. J. Geophys. Res., 110, D24112, https://doi.org/ 10.1029/2005JD006150.

, and D. J. Seidel, 2005: A global comparison of surface and free-air temperatures at high elevations. J. Geophys. Res., 110, D03104, https://doi.org/10.1029/2004JD005047.

_ - and Coauthors, 2015: Elevation-dependent warming in mountain regions of the world. Nat. Climate Change, 4, 424430, https://doi.org/10.1038/nclimate2563.

Price, J. D., and Coauthors, 2011: COLPEX: Field and numerical studies over a region of small hills. Bull. Amer. Meteor. Soc., 92, 1636-1650, https://doi.org/10.1175/ 2011BAMS3032.1.

_- , and Coauthors, 2018: LANFEX: A field and modelling study to improve our understanding and forecasting of radiation fog. Bull. Amer. Meteor. Soc., https://doi.org/ 10.1175/BAMS-D-16-0299.1, in press.

Sheridan, P. F., and S. B. Vosper, 2005: Numerical simulations of rotors, hydraulic jumps and eddy shedding in the Falkland Islands. Atmos. Sci. Lett., 6, 211-218, https://doi.org/10.1002/ asl.118.

— waves, rotors and downslope winds. Meteor. Appl., 13, 179195, https://doi.org/10.1017/S1350482706002088.

_ - and — 2014: Dependence of valley cold air pools on valley scale. 16th Conf. on Mountain Meteorology, San Diego, CA, Amer. Meteor. Soc., https://ams.confex.com/ams/16MountMet/ webprogram/Paper251427.html.

, V. Horlacher, G. G. Rooney, P. Hignett, S. D. Mobbs, and S. B. Vosper, 2007: Influence of lee waves on the near-surface flow downwind of the Pennines. Quart. J. Roy. Meteor. Soc., 133, 1353-1369, https://doi.org/10.1002/qj.110. 
S. A. Smith, A. R. Brown, and S. B. Vosper, 2010: A simple height-based correction for temperature downscaling in complex terrain. Meteor. Appl., 17, 329-339, https://doi.org/ 10.1002/met.177.

_ S. B. Vosper, and A. R. Brown, 2014: Characteristics of cold pools observed in narrow valleys and dependence on external conditions. Quart. J. Roy. Meteor. Soc., 140, 715-728, https:// doi.org/10.1002/qj.2159.

Smith, S. A., A. R. Brown, S. B. Vosper, P. A. Murkin, and A. T Veal, 2010: Observations and simulations of cold air pooling in valleys. Bound.-Layer Meteor., 134, 85-108, https://doi.org/ 10.1007/s10546-009-9436-9.

Steinacker, R., and Coauthors, 2007: A sinkhole field experiment in the eastern Alps. Bull. Amer. Meteor. Soc., 88, 701-716, https://doi.org/10.1175/BAMS-88-5-701.

Vosper, S. B., 2004: Inversion effects on mountain lee waves. Quart. J. Roy. Meteor. Soc., 130, 1723-1748, https://doi.org/ 10.1256/qj.03.63.

— valleys: The formation of nighttime cold-air pools. Bound.-Layer Meteor., 127, 429-448, https://doi.org/10.1007/s10546-008-9272-3.

_, P. F. Sheridan, and A. R. Brown, 2006: Flow separation and rotor formation beneath two-dimensional trapped lee waves. Quart. J. Roy. Meteor. Soc., 132, 2415-2438, https://doi.org/ 10.1256/qj.05.174.

, E. Carter, H. Lean, A. P. Lock, P. Clark, and S. Webster, 2013: High resolution modelling of valley cold pools. Atmos. Sci. Lett., 14, 193-199, https://doi.org/10.1002/asl2.439.
— J. K. Hughes, A. P. Lock, P. F. Sheridan, A. N. Ross, B. Jemmett-Smith, and A. R. Brown, 2014: Cold pool formation in a narrow valley. Quart. J. Roy. Meteor. Soc., 140, 699714, https://doi.org/10.1002/qj.2160.

Whiteman, C. D., and Coauthors, 2008: METCRAX 2006: Meteorological experiments in Arizona's Meteor Crater. Bull. Amer. Meteor. Soc., 89, 1665-1680, https://doi.org/10.1175/ 2008BAMS2574.1.

— , S. Eisenbach, B. Pospichal, and R. Steinacker, 2004a: Comparison of vertical soundings and sidewall air temperature measurements in a small Alpine basin. J. Appl. Meteor., 43, 1635-1647, https://doi.org/10.1175/JAM2168.1.

—, T. Haiden, B. Pospichal, S. Eisenbach, and R. Steinacker, 2004b: Minimum temperatures, diurnal temperature ranges, and temperature inversions in limestone sinkholes of different sizes and shapes. J. Appl. Meteor., 43, 1224-1236, https://doi.org/ 10.1175/1520-0450(2004)043<1224:MTDTRA > 2.0.CO;2.

—, S. W. Hoch, J. D. Horel, and A. Charland, 2014: Relationship between particulate air pollution and meteorological variables in Utah's Salt Lake Valley. Atmos. Environ., 94, 742-753, https://doi.org/10.1016/j.atmosenv.2014.06.012.

Wood, N., and P. J. Mason, 1993: The pressure force induced by neutral, turbulent flow over hills. Quart. J. Roy. Meteor. Soc., 119, 1233-1267, https://doi.org/10.1002/qj.49711951402.

Zhang, C., Y. Wang, K. Hamilton, and A. Lauer, 2016: Dynamical downscaling of the climate for the Hawaiian Islands. Part I: Present day. J. Climate, 29, 3027-3048, https://doi.org/10.1175/ JCLI-D-15-0432.1. 